NBER WORKING PAPER SERIES

\title{
LANDMINES AND SPATIAL DEVELOPMENT
}

\author{
Giorgio Chiovelli \\ Stelios Michalopoulos \\ Elias Papaioannou \\ Working Paper 24758 \\ http://www.nber.org/papers/w24758
NATIONAL BUREAU OF ECONOMIC RESEARCH
1050 Massachusetts Avenue
Cambridge, MA 02138
June 2018

We thank UK's Department of Foreign International Development (DFID) and the Centre for Economic Policy Research (CEPR) for generous funding via the PEDL programme. We are grateful to London Business School Institute for Innovation and Entrepreneurship for supporting this research, as well as the UK’s EPSRC.

A special thanks to Sebastian Hohmann for help in various phases and aspects of this project. We would like to thank Suzana Moreira and the MoWoza team for helping us collect and organize some of the data. We would like to thank all demining operators involved in the Mine Action program in Mozambique and, in particular, APOPO, HALO Trust, Handicap International (Humanity and Inclusion), and Norwegian's People Aid for kindly sharing the original data on their interventions and generously sharing their expert knowledge and on-the-ground experience. This project could not have been completed without the generous support of many dedicated individuals.

We are thankful to Olivier Cottray, Anne-Li Naucler, and Wendi Pedersen from the Geneva International Center for Humanitarian Demining (GICHD) for assisting us in various stages of this project.

We are truly grateful to Alberto Maverengue Augusto from Mozambique's National Institute of Demining; Mica Bevington, Jean-Baptiste Richard, and Gilles Delecourt, Alma Al Osta, and Emanuel Sauvage from Humanity and Inclusion; Camille Wallen and Rachel Boddy from HALO Trust; Afedra Robert Iga and Hans Peter Risser from NPA; Ashley S. Fitzpatrick and Tess Tewelde from APOPO; Chris Pearce and Richard Holmes from Dynasafe; Manuel Sitoe from UNADP. A special thanks goes to Aderito Ismael (HI) and Ulrich Weyl (GTZ) for helping us understanding the history and technical aspects of demining in Mozambique. 
We are also thankful to Greek-Orthodox Diocese Archbishop of Zambia, Malawi, and Mozambique Ioannis, Stergios Varvaroussis from the EU mission in Maputo, and Maro Spanoudi.

We thank Alberto Marden da Cruz, Novella Maugeri and Jorrit Oppewal from the International Growth Center. We thank Antonio Francisco from the Instituto de Estudos Sociais e Economicos (IESE).

Panos Kosmas and Jamie Barras kindly shared their technical expertise on landmine detection and removal technology.

We also thank Patrick Domingues for kindly sharing his data on the civil war incidents.

We thank for comments and valuable feedback Francesco Amodio, Costas Arkolakis, Lorenzo Casaburi, Alejandro Cunat, Francesco Caselli, Ruben Enikolopov, Remi Jedwab, Nuno Limao, Ted Paterson, Thorsten Persson, Yannick Pengl, Ricardo Reis, Thodoris Rapanos, Sandra Sequeira, Ina Simonovska, Silvana Tenreyro, Jaume Ventura, Joachim Voth, and Austin L. Wright. We also thank Chris Woodruff for his support.

We also thank seminar participants at the 15th Meeting of State Parties to the Mine Ban Treaty, Brown, UPF-CREI, CSAE Conference at Oxford University, EIEF, Harvard, IIES, Maryland, George Washington, John Hopkins, Zurich, Vienna, Macedonia, Glasgow, King's College, McGill, Mondlane, LBS, LSE (macro), the 20th National Directors' Meeting at UN Mine Action, NBER's Economics of National Security Meeting, Queen Mary, Sussex, Universidad Catolica del Uruguay, Universidad de Montevideo, and "Geodata in Economics" workshop at the University of Brunswick -- Institute of Technology, and the IGC-PEDL-LSE conference. All errors are our responsibility. The views expressed herein are those of the authors and do not necessarily reflect the views of the National Bureau of Economic Research.

NBER working papers are circulated for discussion and comment purposes. They have not been peer-reviewed or been subject to the review by the NBER Board of Directors that accompanies official NBER publications.

(C) 2018 by Giorgio Chiovelli, Stelios Michalopoulos, and Elias Papaioannou. All rights reserved. Short sections of text, not to exceed two paragraphs, may be quoted without explicit permission provided that full credit, including (C) notice, is given to the source. 
Landmines and Spatial Development

Giorgio Chiovelli, Stelios Michalopoulos, and Elias Papaioannou

NBER Working Paper No. 24758

June 2018

JEL No. N17,O0,O1,O10,R0

\begin{abstract}
Landmine contamination affects the lives of millions in many conflict-ridden countries long after the cessation of hostilities. Yet, little research exists on its impact on post-conflict recovery. In this study, we explore the economic consequences of landmine clearance in Mozambique, the only country that has moved from "heavily-contaminated" in 1992 to "mine-free" status in 2015. First, we compile a dataset detailing the evolution of clearance, collecting thousands of reports from the numerous demining actors. Second, we exploit the timing of demining to assess its impact on local economic activity, as reflected in satellite images of light density at night. The analysis reveals a moderate positive association that masks sizeable heterogeneity. Economic activity responds strongly to clearance of the transportation network, trade hubs, and more populous areas, while the demining-development association is weak in rural areas of low population density. Third, recognizing that landmine removal reconfigured the accessibility to the transportation infrastructure, we apply a "market-access" approach to quantify both its direct and indirect effects. The market-access estimates reveal substantial improvements on aggregate economic activity. The market-access benefits of demining are also present in localities without any contamination. Fourth, counterfactual policy simulations project considerable gains had the fragmented process of clearance in Mozambique been centrally coordinated, prioritizing clearance of the colonial transportation routes.
\end{abstract}

Giorgio Chiovelli

London Business School

Regent's Park

London, NW 4SA

United Kingdom

gchiovelli@london.edu

Stelios Michalopoulos

Brown University

Department of Economics

64 Waterman Street

Providence, RI 02912

and NBER

smichalo@brown.edu
Elias Papaioannou

London Business School

Regent's Park

Sussex Place

London NW1 4SA

United Kingdom

papaioannou.elias@gmail.com

A data appendix is available at http://www.nber.org/data-appendix/w24758

A Website is available at www.land-mines.com 


\section{Introduction}

The millions of refugees escaping conflict-ridden regions in recent years has added urgency in understanding (the absence of) growth in the aftermath of conflict. Shedding light on the factors that enable a swift post-conflict recovery is vital, since sluggish growth may push a war-torn region back to the vicious circle of violence and poverty (IGC (2018)). The consequences of conflict are multifaceted permeating all aspects of the societal fabric; loss of lives, injuries, the destruction of infrastructure, distrust, and the deterioration of institutional capacity, among others. Nevertheless, one conspicuous legacy of conflict is that of landmine and other unexploded ordnance (UXOs) contamination. ${ }^{1}$

"Peace agreements may be signed and hostilities may cease, but landmines and explosive remnants of war are an enduring legacy of conflict" states in its introduction the 2017 Landmine Monitor. In spite of landmines' extensive use in civil wars post World War II and the salience of this topic for the international community, ${ }^{2}$ there has been little research quantifying their role in post-conflict recovery. This paper aims to start filling this gap by focusing on Mozambique, the only country so far that has moved from "heavily contaminated by landmines" in 1992 to "landmine free" status in 2015.

Landmines have been coined "the weapon of the poor", as they cost as little as one dollar and can be manufactured by militias at an even smaller cost. Pol Pot, Cambodia's Khmer Rouge infamous leader reportetly argued that " a landmine is a perfect soldier, it doesn't need food or water, it doesn't take any salary or rest, and it will lie in wait for its victim." Hence, it is not surprising that they have been extensively used in many civil wars; among others, in Cambodia, in Angola, in Congo, in Colombia, in Afghanistan, in the Caucasus region, and during the breakup of Yugoslavia. Human Rights Watch estimated in 1993 that in the previous 25 years, 5 million mines were manufactured globally. Today mine contamination remains a serious threat in more than 50 countries, most importantly in Angola, Afghanistan, Cambodia, Somalia, Sudan, but also in frontier/developing economies, including Colombia, El Salvador, Nicaragua, Ukraine, and Myanmar (Landmine Monitor, 2015, 2016, 2017). Media reports suggest widespread ongoing use in Syria, Iraq, Libya, Yemen, and Myanmar. ${ }^{3}$

Landmines are a particularly damaging legacy of wars, as they remain active, hidden on the ground long after the cessation of hostilities posing an incessant threat to the population. According to Graca Machel, an expert of the UN Secretary-General on the "Impact of Armed Conflict on Children" and former minister of education of Mozambique "landmines are uniquely savage in the history of modern conventional warfare not only because of their appalling individual impact, but also their long-term

\footnotetext{
${ }^{1}$ Landmines are containers of explosive material with detonating systems that are triggered by contact with a person or vehicle. They are designed to incapacitate that person or vehicle through damage caused by an explosive blast, fragments, or, in the case of some antitank mines, a jet of molten metal.

${ }^{2}$ Its importance can be glimpsed by the NGOs, government agencies, donors and commercial partners that engage in mine-related activities. There are 14 agencies under the auspices of the UN mine-action program, which as of 2008 was active in 43 countries. Conservative estimates put the annual budget of landmine and UXO clearance to an average of 700 million USD (Landmine Monitor, 2016).

${ }^{3}$ The use of landmines has been quite extensive in the context of international wars, including WWI and WWII. Nevertheless, conventional armies, unlike warring parties in civil wars, keep records of minefields that greatly facilitate their clearance.
} 
social and economic destruction" (UN General Assembly Resolution 48/157, 1996). The Landmine Monitor has recorded more than 110,000 mine/UXO fatalities since its (partial) global tracking in 1999 and -if anything- these are underestimates as landmine casualties go often unrecorded due to states' weak capacity, misgovernance, and misreporting in hospitals and clinics (Landmine Monitor (2017), Ascherio et al. (1995)). ${ }^{4}$

\subsection{Results Preview}

We examine the impact of landmine and UXO clearance on the Mozambican economy that emerged in 1992 from 25 years of warfare severely damaged with hundreds of thousands of landmines across roughly 7,000 minefields scattered across its vast territory. In September 2015, with support from international agencies, foreign governments, and the strength of the Mozambican people, Mozambique was officially declared "landmine free". 5

Our analysis proceeds in six steps. First, we present the self-collected cross-validated data on thousands of clearance operations, conducted by dozens of demining actors. We are able to provide the first (almost) complete documentation of landmine and UXO clearance for any country in the world, a non-negligible contribution as such data are not available from any government or the United Nations.

Second, we examine the correlates of the spatial distribution of minefields and the timing of their clearance looking at the role of end-of-war (in 1992) and at-independence (in 1975) factors. In line with interviews with practitioners and the historical narrative (discussed briefly below and in detail in the Online Appendix) on the localized and fragmented nature of clearance operations, we find that the timing of demining is weakly related to geographic, location, and economic characteristics.

Third, we exploit variation in the timing of landmine clearance across localities to assess its impact on local economic activity. To bypass data unavailability (especially in the 1990s when Mozambique was among the poorest nations in the world), we use satellite images of light density at night that are available at a fine spatial resolution and yearly frequency since 1992 and have been shown to be good proxies of development (see Henderson, Storeygard, and Weil, 2012). We compare luminosity in localities, where demining took place in a given year/period, to those localities that were either not contaminated or were mined but not cleared yet. The analysis shows that local economic activity picks up modestly upon the removal of landmines and UXOs.

\footnotetext{
${ }^{4}$ Ascherio et al. (1995) conducted surveys in two Mozambican provinces shortly after the war ending and estimated ratios of fatal and non-fatal landmine injuries of $8.1-8.2$ per 1,000 (roughly $3.8^{0} \%$ deaths, $3.2^{0} / 00$ amputations, and $1.1^{0} / 00$ other injuries). These estimates are ten-times higher than the one based on hospital or amputee-assistanceprogrammes. Roughly $75 \%$ of fatalities happen before the victim reaches a health center.

${ }^{5}$ HALO Trust (2007) provides the definition of landmine free, "That is not to say that there are no more mines remaining. Unfortunately the manner in which the war was conducted means that mines may remain in isolation which nobody alive knows anything about, and their presence will go undetected until such time that they explode or are uncovered. But, nevertheless, there are no more areas left to demine, nobody in the north of the country can point at an area and say 'I think there are mines there".
} 
Fourth, we explore heterogeneity to shed light on the mechanisms at work. Demining interventions in agricultural, low population density areas have no readily discernible impact on local development (at least as captured by images of satellite density). In contrast, clearance of relatively densely populated localities, regions hosting trade hubs, and localities along the main transportation network translates into substantial improvements in economic activity.

Fifth, we examine the economy-wide consequences of landmine clearance recognizing the fact that removing landmines in one locality may impact economic activity in other regions via transportation network linkages. Employing recently developed techniques in quantitative trade (e.g., Eaton and Kortum (2002), Arkolakis, Costinot, and Rodríguez-Clare (2012), Donaldson and Hornbeck (2016), Donaldson (2018)), we apply a "market-access" approach that captures both the direct and indirect effects of clearance. The analysis reveals economically large and statistically precise effects of landmine removal. Spillovers are strong, as the "market access" - luminosity elasticity is highly significant even in localities that were spared from landmine contamination. We also examine the association between localities' market access and luminosity looking at clearance interventions targeting the atindependence infrastructure network and imposing the pre-civil-war distribution of the population. The estimates ["beta" coefficients of around $0.2-0.3$ ] are in line with the estimates of the effect of large infrastructure projects in other contents, such as the extensions of railways in the United States in late 19th century (Donaldson and Hornbeck (2016)) or the Golden Quadrilateral highway system in India in the 2000s (Alder (2017)).

Sixth, we conduct counterfactual policy simulations to assess the effect of landmine clearance. As a starting point, we approximate how much luminosity would have increased in absence of any landmine clearance, finding that in this extreme case aggregate light density in 2015 would have been roughly $70 \%$ lower. Given a light-GDP elasticity of around 0.3 (Henderson, et al. 2012), this translates into an output boost of around 20\%. We then approximate the costs of the fragmented and non-coordinated nature of landmine clearance process that (especially in the early stages) took place under chaotic conditions and was further impeded by devastating floods in $2000-2001$, corruption, and donor fatigue in the mid-2000s. We estimate a counterfactual landmine removal plan that prioritizes the three colonial "corridors" connecting the three main ports (Maputo, Beira, and Nacala) with the mainland, followed by the clearance of the highway connecting the south to the central regions, and finally clearing the rest of the contaminated areas. The comparison of actual demining with this heuristic counterfactual reveals substantial losses from the absence of central, strategic prioritization; in the early years, Mozambique cleared border areas and rural regions rather than infrastructurenetwork-central localities or local urban/trade hubs.

\subsection{Related Literature}

There is little research assessing the role of landmine clearance on the local economy and none on its aggregate consequences. Our study connects to many strands of research that have evolved, however, 
in parallel.

First, our findings contribute to our understanding of the economic legacy of civil wars (see Blattman and Miguel (2010) for a thorough overview). Works based on cross-country comparisons and case studies (e.g., Collier and Hoeffler (2007), Collier and Sambanis (2005)) show that civil wars slow down economic activity; and, while, typically growth resumes at the end of conflict, the strength and timing of the recovery varies considerably. ${ }^{6}$ Landmine contamination and the speed at which it is cleared may partially account for the observed heterogeneity, yet there is not much work. Exceptions are Merrouche (2008), who presents cross-sectional correlations across 126 Mozambican districts between contamination and poverty rates and Arcand, Rodella-Boitreaud, and Rieger (2014), who using survey data from Angola document significant cross-district associations between contamination and malnutrition. ${ }^{7}$ Besides focusing on the consequences of landmines, an important, but unexplored consequence of civil warfare, we bring into this body of research a theoretically-grounded approach that allows quantifying spatial spillovers. This may be important, as most within-country empirical studies exploit regional variation in a "control"- "treatment" framework that works well when spatial inter-dependencies are absent (weak). In our context, we find that landmine clearance by shaping population dynamics and economic activity, generates sizeable spatial externalities. ${ }^{8}$

Second, from a methodological standpoint our paper relates to recent works in trade and urban economics that apply insights from general equilibrium trade theory to study the aggregate, direct and indirect, effects of transportation infrastructure on economic activity (see Donaldson (2015) for an overview). In an important paper, Donaldson and Hornbeck (2016) adopt the Ricardian model of Eaton and Kortum (2002) to derive a "reduced-form" expression linking changes in regional welfare (income) to changes of a region's market access, that reflects its proximity via the transportation system to all other markets, scaled by population and income. They then document that aggregate effects of the railroad expansion in the US during the 19th century are considerably larger than local effects, which influential earlier research by Fogel (1964) had estimated as being small. A similar approach has been applied in a variety of other contexts including the building of colonial railroads in India, Donaldson (2018), the construction of large Indian highways, Alder (2017), and the role of road construction in Sub-Saharan Africa during the post-colonial era, Jedwab and Storeygard (2018).

\footnotetext{
${ }^{6}$ From a theoretical standpoint, the post-war speed of recovery is ambiguous. In the canonical neoclassical model, economic activity rebounds quickly and the recovery is strong, if the war has mostly destroyed physical capital (as it is our case). Yet, in absence of external interventions, recovery is sluggish in "poverty-trap" models that are commonly used/assumed in development policy circles (e.g., Sachs (2005), Duflo and Banerjee (2011)).

${ }^{7}$ There is also some connection between our paper and studies of the impact of bombardment. Miguel and Roland (2011) and Dell and Querubin (2017) quantify the long-run effects of the bombing of Vietnam on the economy, local governance, and insurgency. Lin (2016) shows that the average effect of bombing Cambodia is on average small but considerably negative in soil-rich areas Davis and Weinstein (2002) look at the economic geography after the WWII bombing of Japan.

${ }^{8}$ Exploiting the infrastructure network structure of Mexico, Dell (2015), for example, shows significant spillovers of drug-related violence and trafficking when enforcement increases. Harari and La Ferrara (2018) show sizable spillovers between climate shocks and conflict. Michalopoulos and Papaioannou (2016a) show that conflict in Africa spreads from partitioned by the national border ethnic homelands to nearby regions.
} 
We employ a "market access" approach to examine an understudied issue, the removal of landmines and other explosive war remnants. This framework appears useful in addressing some policy-relevant questions. What are the aggregate, as opposed to local, effects of removing landmines? How shall NGOs, international organizations, and governmental agencies design the clearance of minefields once the war is over, a critical issue nowadays in Cambodia, Colombia, and other countries?

Third, our focus on the legacy of a devastating civil war that left Mozambique contaminated with hundreds of thousands of landmines connects our work to the broader agenda on the origins of African (under)-development (see Bates (2007) and Collier and Gunning (1999) for overviews of the role of post-independence policies and Michalopoulos and Papaioannou (2016b) for a review of the burgeoning literature on historical legacies). Since landmine clearance is often funded by foreign donors and development agencies (as in Mozambique), there is also some relation of our work with the large literature on foreign aid (see Easterly (2009) and Easterly and Pfutze (2008) for reviews). Finally, our paper contributes to practitioner/applied works on the topic (e.g., Cameron, Gibson, Helmers, Lim, Tressler, and Vaddanak (2010), Keeley (2006) and Elliot and Harris (2001)) and the mostly qualitative studies of demining operators and development agencies (summarized in the annual editions of Landmine Monitor).

\subsection{Paper Structure}

The paper is structured as follows. In the next section we provide an overview of the use of landmines in Mozambique and the 23-year-long process of clearance. Since there is not much research on landmines, we have moved a lot of material in online supplementary appendixes that we briefly discuss below. In Section 3 we present the self-collected data on landmine clearance. In section 4 we report the "difference-in-difference" specifications and explore heterogeneity of the correlation between luminosity and landmine clearance. In section 5 we report the market-access estimates that quantify the direct and indirect effects of landmine clearance. In section 6 we present the counterfactual policy experiments that quantify the role of landmine clearance on economic activity and the losses from the absence of coordinated prioritization. In section 7 we discuss the implications of our findings and offer some thoughts on future research.

\section{Historical Background}

This section provides a brief account of the use of landmines (1964-1992) and the subsequent clearing efforts, a process that lasted more than twenty years $(1992-2015)$. In Appendix $I$ we provide an overview of the Mozambican war of independence (1964-1974) and the ensuing civil war (1977-1992), discussing the strategic objectives of the parties and the use of landmines. In Appendix $I I$ we provide a detailed description of the gigantic landmine clearance process. 


\subsection{Conflict and Landmine Use}

Mozambique's experience with landmines starts with the war of independence. The Portuguese planted large minefields along the border with Tanzania to prevent the fighters of the Front for Liberation of Mozambique (FRELIMO), the main independence movement, to enter the country. The colonial administration also planted mines along key infrastructure to protect them from the insurgents, including the largest minefield in Africa, of 80,000 mines, along the Cahora-Bassa dam. In turn, FRELIMO used landmines for military purposes, to demoralize the colonial army, destabilize the countryside, and to cut road communications (Human Rights Watch (1997)). Mozambique becomes independent in 1975. But conditions deteriorate, as the country enters one of the most disruptive civil wars since WWII. The main warring parties, FRELIMO that was now in government, backed by socialist countries, and the Mozambique Resistance Movement (RENAMO), supported initially (1977 - 1980) by Rhodesia and subsequently from South Africa's apartheid regime, used extensively landmines for military purposes, to protect infrastructure (e.g., electricity pylons and roads), to terrorize the civilian population, to shield borders and block rearmament, and to ring-fence towns, villages, and farms. Between the late 1970s and the early 1990s, FRELIMO and RENAMO disseminated landmines in a wholesale fashion mostly targeting civilians (Human Rights Watch (1997)). Militias, thugs, and other groups also used landmines in their strategy of terror and for a plethora of other reasons. ${ }^{9}$

\subsection{Mozambique at the End of the War (1992). The Problem of Landmines}

Mozambique was destroyed at the end of the civil war. According to the Penn World Table statistics, it was the third poorest country in the world; a Human Rights Watch (1992) report suggested that "parts of the country had returned to the stone age and Mozambique has to be built from scratch." Landmines and unexploded ordnance posed massive problems and interacted crucially with other devastating consequences of the civil war. Mozambican refugees in neighboring countries (approximately 1.5 million) and internally displaced people (roughly 3 million out of a total population of around 15 million) could not return to their homes, as they did not know whether the roads were safe or whether their villages were mined. Initial assessments put the number of landmines to millions. Contamination was widespread along the main transportation routes. Electricity pylons, dams, and power stations were also heavily mined. A country with one of the most advanced hydroelectric dams in the world -that was meant to provide energy also to neighboring countries- was without electricity. Mines had been planted around schools, police stations, and other government buildings, typically used as the local rebel or government headquarters. While there is no reliable data, early reports suggest thousands of mine-related accidents (some estimates put the death toll to 30,000). Recognizing this challenge the General Peace Accord signed in Rome in September 1992 required in Protocol VI that FRELIMO

\footnotetext{
${ }^{9}$ The use of landmines by all parties is corroborated by the origin of manufacture. Landmines come from different countries, including Portugal, Russia, USA, Britain, Czechoslovakia, Hungary, Italy, South Africa, Belgium, France, and China.
} 
and RENAMO "organize and implement mine-clearing operations" and provide assurances that they will not "prevent mine-clearing operations."

HALO Trust' 1994 survey, conducted for the United Nations Office for Humanitarian Assistance Coordination, provides an early account of the extent of contamination. First, the problem was mostly on the extensive -rather than the intensive- margin, as the "use of landmines in Mozambique is characterized by a highly dispersed pattern". The report suggested a "figure of hundreds of thousands [mines] is probable" (Halo Trust (1994)). While the report was incomplete (as many parts of the country were inaccessible) and only partially identified landmine-affected areas, subsequent more-indepth reports corroborated the dispersed nature of landmine placement. A handful of mines can have adverse effects. For example, eight mines cleared in 1996 were preventing 20,000 people of the entire Mahniça valley (in the Maputo province) from returning to their villages. Human Rights Watch 1997 report makes a similar point. "During a Norwegian Peoples Aid mine clearance operation in Maputo province, a team was sent in 1994 to clear the village of Mapulenge, which had been the center of a community of about 10,000 people. It had been deserted for some four years because it was locally believed to be heavily mined. After three months of work, the clearance team reported finding four mines; these, and the rumor of many more, were sufficient to depopulate the entire area." Second, infrastructure was heavily mined; the reported stated that in the southern and central provinces "all dams, railway lines, electricity substations and pylon lines should be assumed to be mined" and a similar though somewhat better assessment carried for the northern districts. Third, the survey pointed out that the actual number of landmines is "not of great importance", as "what matters is the number of areas which the population believes to be mined and therefore do not enter." Fourth, UXOs posed also a challenge, as due to rainfall and landslides, they would move around, blend with mud, and become hard to detect.

\subsection{Landmine Clearance}

\subsubsection{Land Release Process}

Mines are usually buried within 15 centimeters of the earth's surface, which makes verification a difficult task. Even for mines laid on the ground, detection is hard, as vegetation grows and floods and rock-slides move landmines. Detection becomes even harder as surveyors in most cases search for landmines placed years ago by actors that often are not around anymore. Before reviewing the process of clearance operations in Mozambique, it is useful to describe the land release process in case of suspected contamination.

Over time, the mine action community has acknowledged that attempting to clear all areas suspected of contamination (known as "suspected hazardous areas" - SHA) is infeasible. The initial classification of SHA is often based on word-of-mouth collected well after their plantation, typically under insecure conditions. Cancelling "false positive" SHA or updating their status to confirmed haz- 
ardous areas (CHA) is an essential task, typically done via non-technical surveys (NTS). NTS gather and analyze information by visiting the area, interviewing landowners, farmers, village leaders, and (ex) military personnel. In cases of sufficient evidence of contamination, a technical survey (TS) that collects more precise information follows. Usually, a TS concludes with the clearance of the hazard(s) and the issuing of a completion report. TS detection methods are similar to those used in clearance; they include manual labor, animal detection, flail and tiller machines, trollers, and wide-area detectors like magnetometers.

These practices first came into place at the end of 2001 with the issuance of the Handbook of International Mine Action Standards (IMAS), last revised on February 2016. ${ }^{10}$ Hence, it is in the absence of best practices and little coordination among demining actors that one needs to understand clearance operations in Mozambique during the 1990s and early/mid-2000s.

\subsubsection{Phase 1. $(1992-1999)$}

The 1992 Peace Accord specified that UN soldiers and workers had to work with national authorities to coordinate and conduct clearance. However, the UN was unprepared for this huge task and the government was weak (GICHD (2005)). The UN wanted to establish its own mine action unit, but donors were skeptical and preferred to proceed with specialized NGOs. Humanitarian operators were left at their own, with no direction. UN initiatives were prevented or delayed by FRELIMO and RENAMO, as well as internal-bureaucratic frictions (Human Rights Watch (1997)). In the early stage leading to the 1994 elections, there were just a few interventions targeting war camps (inside and just outside the country) and some border roads, as priority was given to the return of refugees.

Since 1994, demining operations emerged along three geographically distinct areas and "humanitarian" programmes (GICHD (2005)). First, The HALO Trust, a British-American NGO, started operating in the northern provinces. By 1999, it was employing close to 200 deminers. Second, the Norwegian People's Aid (NPA) started demining in the central provinces in 1993; by 1999, NPA was employing close to 500 deminers. Since 1998 Handicap International (HI, recently renamed Humanity and Inclusion), an international humanitarian network, also started clearance in Inhambane and subsequently in Sofala. Third, with the help of the UN, the government established the Accelerated Demining Program (ADP) in 1995 that contracted with small commercial operators and NGOs targeting the southern provinces of Maputo, Gaza, and later Inhambane. ADP was quite slow in clearing contaminated areas and in the initial stage it mostly focused on training. By the end of 1998, ADP employed 10 platoons of 50 deminers each.

The first phase can be characterized as a preparatory one (GICHD (2005) describes it as a "consolidation" phase); the country established centers for training, operators started conducting technical surveys, and a few organizations proceeded with demining (North). Besides the minimal progress on

\footnotetext{
${ }^{10}$ IMAS is produced and sponsored by the United Nations Mine Action Service (UNMAS), with the support from a variety of organizations, including the Geneva International Centre for Humanitarian Demining (GICHD).
} 
clearance, the government, the UN, and NGOs had an incomplete and quite fragmented picture of the problem. Osório Mateus Severino, director of Mozambique's mine clearance operations describes the situation in 1997: "We must have a clear idea of what the landmine situation in Mozambique is. We are in the dark about that, and without a sound knowledge of the situation, it is impossible to define a strategy, let alone determine the cost and resources needed for clearance operations" (Human Rights Watch (1997)).

\subsubsection{Phase 2. $(1999-2006)$}

The establishment of the National Demining Institute (IND) in 1999 marks the beginning of the second phase of demining. Besides better local administration, donor funding increased from approximately $5-8$ million per year in $1993-1996$ to around 15 million during $1999-2004$. The IND commissioned a countrywide survey in 2001. Mozambique's Landmine Impact Survey (MLIS) found that landmines affected 123 out of 128 districts in all provinces. MLIS recorded 1,374 SHA totalling roughly 560,000,000 square meters. Approximately 3 million people lived in communities with at least modest contamination. While the survey had flaws, ${ }^{11}$ it provided some guidance and served as a ky input for Mozambique's first five-year (2002 - 2006) mine-action plan.

Sadly, when landmine clearance gained momentum, Mozambique experienced devastating floods in 2000 in the Southern provinces killing about 600 people, displacing more than 200, 000 and affecting the lives of about two million. A major flood hit the central provinces the next year. These events stretched the government's administrative capacity and by moving landmines and UXOs complicated detection and eventual clearance.

Moreover, allegations for corruption erupted in 2003 that led to donor fatigue. Some operators suspended their operations and international funding declined from about 20 million in 2002 to 5 million in 2007. The UN's collaboration with the IND ended in 2005, leaving the best-trained staff unpaid. As a consequence, demining proceeded slowly in the southern and central provinces. The second phase ends, however, with a considerable success, as HALO Trust declared in 2007 the northern provinces as "landmine-free".

\subsubsection{Phase 3. $(2007-2015)$}

The third phase commences with the government's second five-year Mine Action Plan 2008 - 2014 that served as the basis for Mozambique's request for an extension to complete the destruction of anti-personnel mines by 2015 (Government of Mozambique (2008)). This plan was based on $(i)$

\footnotetext{
${ }^{11}$ The Government of Mozambique (2008) summarizes the key challenges: "The large size of Mozambique and the absence of a functional road network in much of it, extensive flooding in parts of the country in 2001, the widespread distribution of mine-affected communities, the absence of comprehensive and accurate national gazetteer (i.e., official listing of communities and their geographic coordinates), the lack of accurate maps and an appropriate scale, the impossibility of applying in its entirety the SAC protocol for false-negative sampling, and, the nature, availability and quality of expert opinion."
} 
2007 Halo Trust Mine Impact Free (MIFD) survey that declared the three northern provinces and Zambezia "landmine free" (Halo Trust (2007)) and (ii) a baseline assessment of conditions in the Southern provinces, based on other operators' (HI and NPA) records (Halo Trust (2007a)). The surveys revealed that in spite of the evident progress, there were three times as many mines than previously thought; more than 600 new mine-contaminated areas were identified. The problem was far from being resolved.

The final phase proceeded well. HALO Trust moved to Maputo in the south and to Manica and Tete in the center. APOPO, a Belgian-Tanzanian NGO experimenting with the use of rats as a cheap and effective technology for detection, also got involved in Gaza and then in Manica. IND also asked HI to move beyond Inhambane and assist in clearing Sofala and Manica (GICHD (2005)). Donors returned as the reports showed that the problem was still acute and because local capacity had improved. Foreign aid for landmine clearance increased fourfold. The last phase is characterized by increased efficiency; the government and NGOs had learned from mistakes and precise technical surveys aided the demining operators. International standardization of processes also helped. The last plan's timeline was respected, and in September 2015 Mozambique was declared landmine free.

\section{Data}

In this Section, we present the newly-compiled data on landmine clearance, the georeferenced infrastructure network, and the proxies of development. Mozambique is divided into 10 provinces and the city of Maputo, the capital. We conduct our analysis across 1, 187 admin- 4 units (localities) ${ }^{12}$ that are the lowest administrative divisions of the country. In terms of land area, Mozambican localities are between municipalities ("cantons") and arrondissements in France and had a median population of 11,515 in 2007.

\subsection{Landmine Clearance}

Our dataset stores 7,423 clearance interventions that have taken place in 6,712 confirmed hazardous areas (CHA) between 1992 and 2015. The vast majority of the CHA (91\%) had exactly one demining intervention, whereas for the remaining 611 CHA (9\% of the sample) there were on average 2.16 interventions (and associated reports). So as not to be pedantic, we will be using interchangeably the notion of a demining intervention and a CHA. Also, the locality-level statistics are derived by aggregating accordingly the 7,423 demining interventions. Overall, we went over around 5,000 completion, clearance and progress reports, as well as technical surveys compiling a dataset that records (almost) all interventions from 1992 till 2015 with as much information as possible.

Below we discuss the data collection, describe some of its features, and provide the mapping of

\footnotetext{
${ }^{12}$ We aggregate the respective localities for Maputo, Matola, Beira, Chimoio, Nampula, and Nacala (population exceeding 200,000). There are 128 districts (admin-2 units) and 405 postos administrativos (admin-3 units).
} 
contamination at the war ending the evolution of clearance operations. Appendix $I I I$ gives details on the data compilation, gives examples, presents summary statistics, and detailed visualizations.

\subsubsection{Data Collection}

We started our data collection by accessing the Information Management System for Mine Action (IMSMA) database stored at the National Institute of Demining (IND) in Maputo. ${ }^{13}$ This database lists suspected and confirmed hazardous areas along with clearance activities at the intervention level. IMSMA data coverage starts in 1993 and ends in October 2015. Coverage, however, is uneven across years. Entries' quality, accuracy, and detail are rather imprecise during the early phase (1993 - 1999), improve somewhat with the MLIS report (2001), and become precise after 2007. IND officials told us that the database is (almost) complete post-2007, but coverage quality declines for the earlier periods. We corrected inconsistencies, deleted duplicates, and going over hand-written reports, we cleaned up the IMSMA data. Overall, our final dataset includes 6,231 interventions from the IND database.

We then collected, processed, and digitized data of the interventions of Halo Trust, HI, NPA, and APOPO, using these organizations' internal records. This served two purposes. First, we validated the IMSMA database entries, making sure that all post-2008 interventions from the main operators were recorded. Second, we expanded coverage in the pre-2007, and especially the pre-2001 period that IMSMA database is incomplete. Specifically, we added 827 interventions from HALO Trust's original dataset and 39 interventions from the NPA. ${ }^{14}$

Subsequently, we retrieved information from the activities of smaller operators in the 1990s. For example, we unearthed 68 clearance operations conducted by GTZ, the German Agency for Technical Operations with MineTech in Manica in the mid-late 1990s (that were again missing from IND's database). We also reached out to former deminers working under the Accelerated Demining Program and reconstructed 35 interventions (missing from the IMSMA dataset). ${ }^{15}$

As clearance in in-between the 1992 peace treaty and the 1994 elections was conducted under the UN, we accessed the the archives of their mission (UNOMOZ) and digitized maps of the early interventions from RONCO, an international firm specializing in humanitarian mine clearance. We also accessed USAID reports and digitized Project Caminho, the main demining operation of the very early phase.

We digitized all Mozambique-wide surveys that aimed to map landmine-affected areas at the time.

\footnotetext{
${ }^{13}$ While this software was not used in Mozambique in the initial phases of demining, IMSMA is currently used by around $80 \%$ of mine-action programmes around the world and is the United Nations preferred information management system for mine action. We are grateful to the Mozambican authorities and IND director, Alberto Maverengue Augusto, for granting us access.

${ }^{14}$ To that end, we visited the NPA warehouse in Tete and accessed all hand-written reports covering $1993-2000$. We went over 70 clearance reports. IND's dataset did not have an entry for 27 interventions that were thus stored as new data. 43 interventions matched the IND database and thus allowed us to validate the accuracy of NPA data in the IMSMA database.

${ }^{15}$ For example, we added: i) interventions on the railway bridge in Magude (Maputo) in 1995; ii) a clearance operation on a trail in Chizapela (Inhambane) in 1998; iii) a demining activity on a military position in Madaucane (Inhambane).
} 
We procured the 1994 HALO Trust Report that identified 981 SHA, the 2000-2001 MLIS report that identified 1,099 SHA, the 2007 HALO Trust baseline report that covered the centre-south provinces, and the 2007 completion survey of clearance operations for the northern provinces. Besides locating suspected hazardous areas (SHA), these reports recorded clearance operations that had taken place in the past and thus allowed supplementing the IMSMA dataset. We added 38 clearance operations from the 2000 - 2001 MLIS and 251 CHA clearance operations from the 2007 "Baseline Assessment" report.

\subsubsection{Report Quality and Characteristics}

The 7,423 confirmed (and eventually cleared) hazardous areas differ considerably. Some interventions regard large in terms of area and number of landmines minefields, as for example, the one stretching the Tanzanian border, cleared by Halo Trust between 2003 - 2006. Others regard the clearance of road segments that could be as long as 208 kilometers (Macata-Malema road cleared by HALO in 2006). Some CHA entail a handful of mines blocking, for example, access to water wells or rivers. Others cover a small area outside schools, townhouses, shops, etc. We leverage this variation, in our estimation.

The details of clearance reports also differ. At the minimum, they include the demining operator (e.g., HI, APOPO), coordinates of contamination, the start and completion date. The average time from start to finish of a demining intervention is 123.2 days; the median is just 8 days, as $41.6 \%$ of all interventions started and finished on the same day. These statistics should be, however, interpreted cautiously. IND officials and deminers alerted us on non-negligible noise on the exact date and timing of intervention, though they argued that the reported year should be fine. Around half of the reports (56\%) provide an estimate of the size of the contaminated area (in square meters), while most post2008 reports also delineate polygons of contamination. The average demining operation cleared 64,949 square meters (a square with a side of 250 meters); while the median is 2,500 square meters. The largest minefield is $45,870,000 \mathrm{~m}^{2}$ (a square with a side of $2.2 \mathrm{~km}$ ). The most complete reports give also information on the number of landmines found (manufacture, type, origin), along with maps, the demining team, the equipment, and a brief description. A typical entry in the database reads, "a minefield covering an area of 18,893 square meters was cleared by Halo Trust on a civil war battle trench nearby Matsinho village in Manica province in 2015".

\subsubsection{Landmine Contamination and Clearance}

Figure 1 - Panel $A$ illustrates the spatial distribution of confirmed hazardous areas across the country. The map, thus, provides an ex-post visualization of the extent of landmine contamination at the end of the civil war. 3,092 clearance operations took place in the third phase of demining (post-2008), 3,418 in the second phase $(2000-2007)$ and 913 in the first phase $(1992-1999)$. 
All provinces are affected, though intensity differs. The most contaminated provinces are Maputo $(1,211)$, Manica (1,053), Inhambane (992), and Sofala (936), areas that RENAMO's operations concentrated in the brutal phases of the civil war in the 1980s. Table 1 gives tabulations by province and period, while Appendix III provides province-specific mappings. There is considerable variability
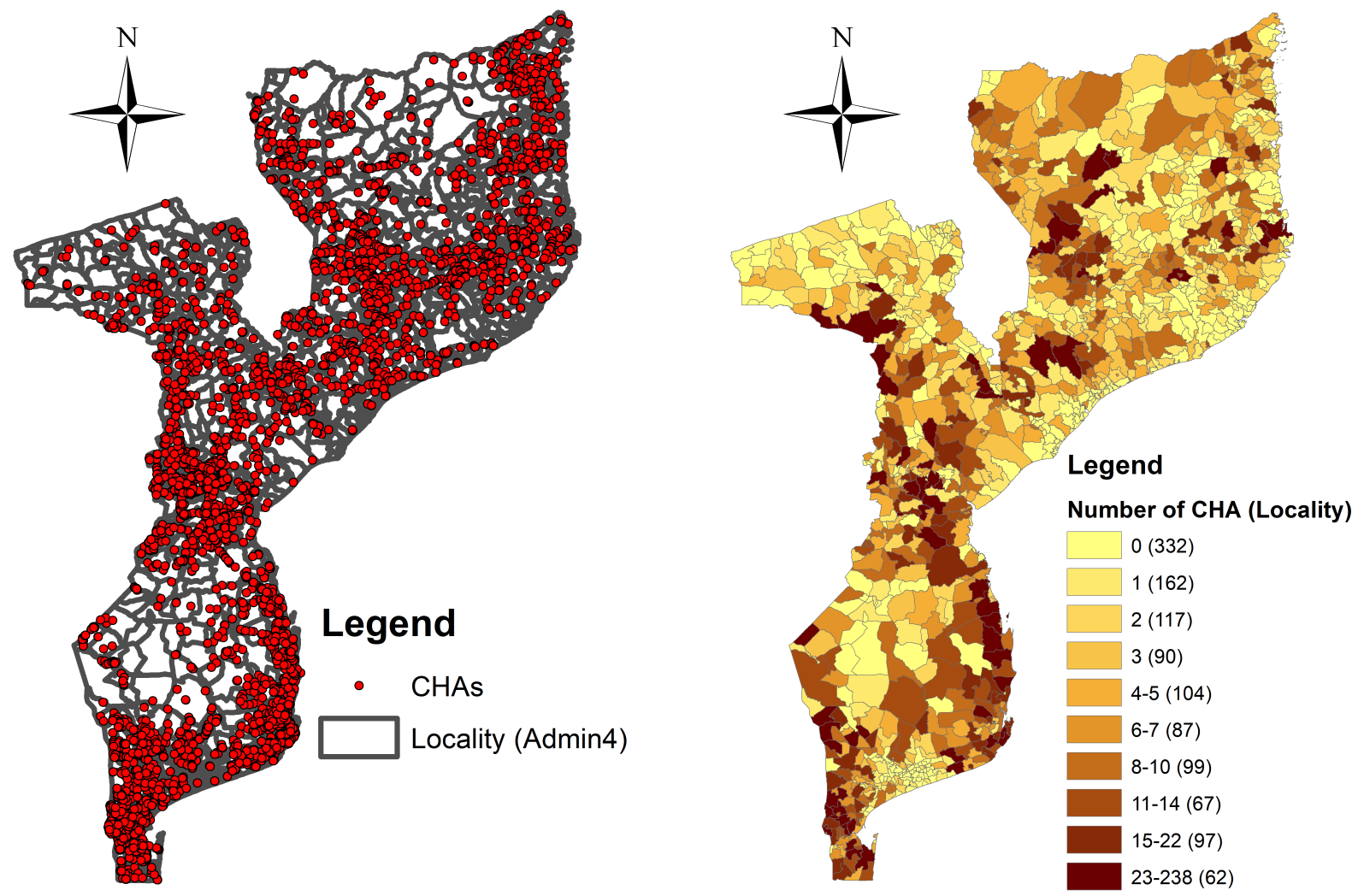

Figure 1: Panel A: Location of CHAs Panel B : CHAs across Localities

also within provinces. Figures $2 a-2 c$ map interventions during the three main phases of demining in Manica, just North of Maputo. Contamination is intense along the railway connecting Harare, Zimbabwe, to the port city of Beira in the Indian Ocean. Contamination is heavy along the paved road connecting the city of Chimoio close to the border with Zimbabwe to the North. In the initial phase, the few interventions were scattered across the province. It is after 1999 that clearance accelerates, targetting, among other places the railroad. The large minefields bordering Zimbabwe in the South-East are cleared in last phase, when also the main cities and the railroad are fully cleared.

For our empirical analysis, we aggregate the data across admin- 4 units. Figure 1 - Panel $B$ illustrates the spatial distribution of confirmed hazardous areas across localities. $72.03 \%$ of localities ( 855 out of the 1,187 ) had at least one contaminated site. The mean CHA is 6.25 with a standard deviation of 14.16. When we focus on the 855 mined localities, the mean (median) is 8.68 (4) with a standard deviation of 16.04. The share of contaminated localities is the highest in Inhambane and 

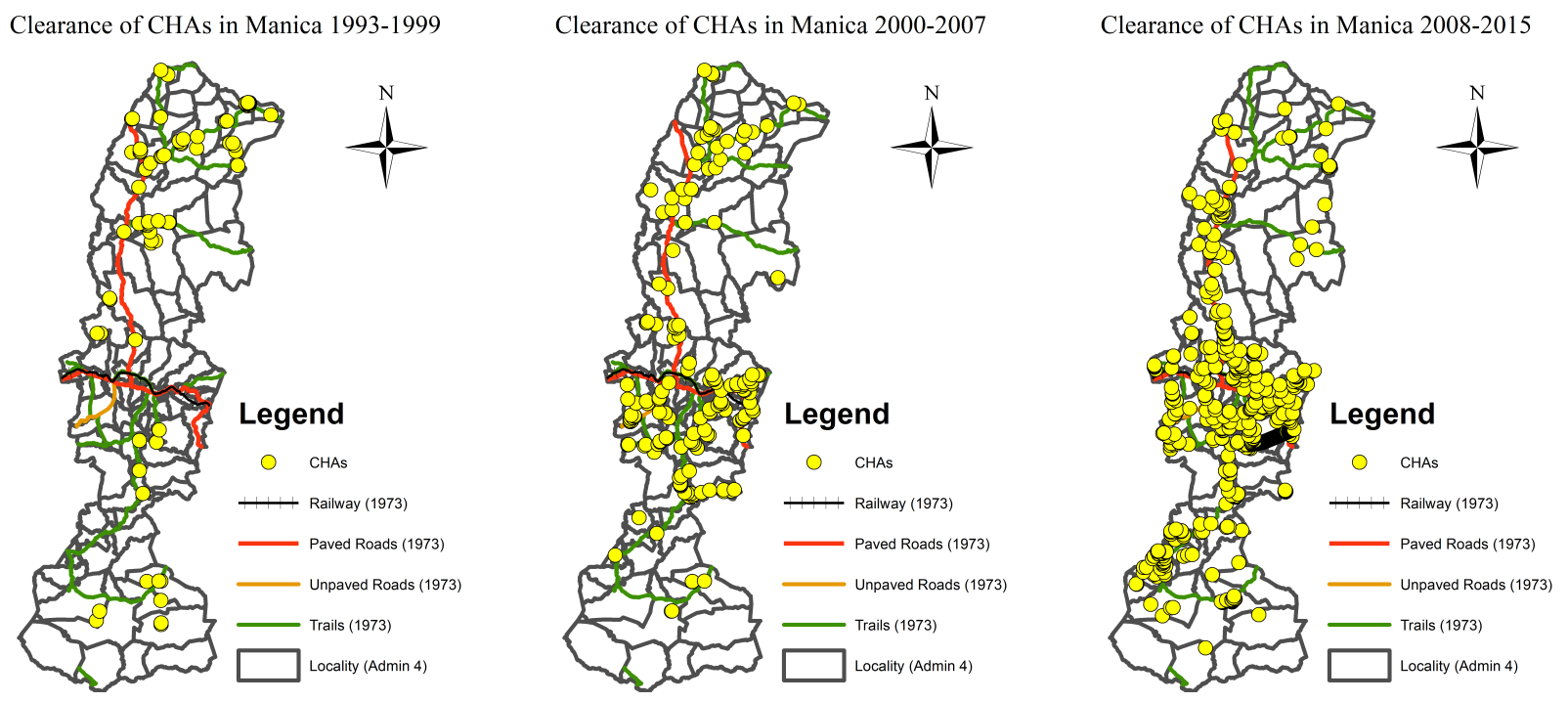

Figure 2: Interventions in Manica

lowest in Tete (see Table 1).

\subsection{Roads and Railroads}

We collected information on the transportation network, roads, railways, bridges, and navigable rivers. From the National Road Administration (ANE) we obtained maps of roads in 2011, with detailed information on their condition (paved, unpaved or trail). We geo-referenced and digitized from the ANE archives data on the conditions and quality of roads for 1998 and 2003. Data for the rail network come from the Ministry of Transport and Communication and other resources. There are three main rail-lines, connecting the coastal areas in the Indian Ocean to inland: the Northern line links Nacala to Malawi; the central line connects Beira to Harare in Zimbabwe; the Southern route goes from Maputo to South Africa (and also to Zimbabwe and Swaziland). A peculiar feature of the Mozambican rail network, intimately connected to its colonial experience, is the absence of any connection among the three main railroads. We also collected data on navigable rivers from the Ministry of Transportation. With the exception of the Zambezi, that effectively cuts the country in the middle, the other rivers do not accommodate large or medium-sized boats. Using archival data, we digitized maps and information on the conditions and quality (paved, unpaved, trail) of the transportation network at independence, in 1973. We also collected information on railroad conditions and status (functioning or destroyed) at the end of the civil war in 1992.

\subsection{Urbanization and Development}

We digitized the pre-clearance, amidst the civil war, population census of 1980, as well as the post-war censuses for 1997 and 2007. From the National Institute of Statistics (INE) we obtained the universe 
of the 11, 196 populated places (villages, towns, cities) of the 1997 census.

Obtaining a reliable, time-varying, high-spatial resolution proxy of economic activity for one of the poorest countries in the world that emerged ruined from years of violence with nominal state capacity, with vast swaths of land virtually inaccessible due to widespread landmine contamination, is a challenge. Following Henderson, Storeygard, and Weil (2012) and subsequent works (summarized in Michalopoulos and Papaioannou (Forthcoming)), we proxy regional development using satellite imagery on light density since 1992 at a resolution of approximately one square kilometer. ${ }^{16}$ Panels $A$ and $B$ of Figure 3 depict the distribution of lit localities in 1992 and 2015, respectively. As of 1992, only $11 \%$ of the districts had some detectable luminosity. This percentage jumps to $42 \%$ in 2015 .
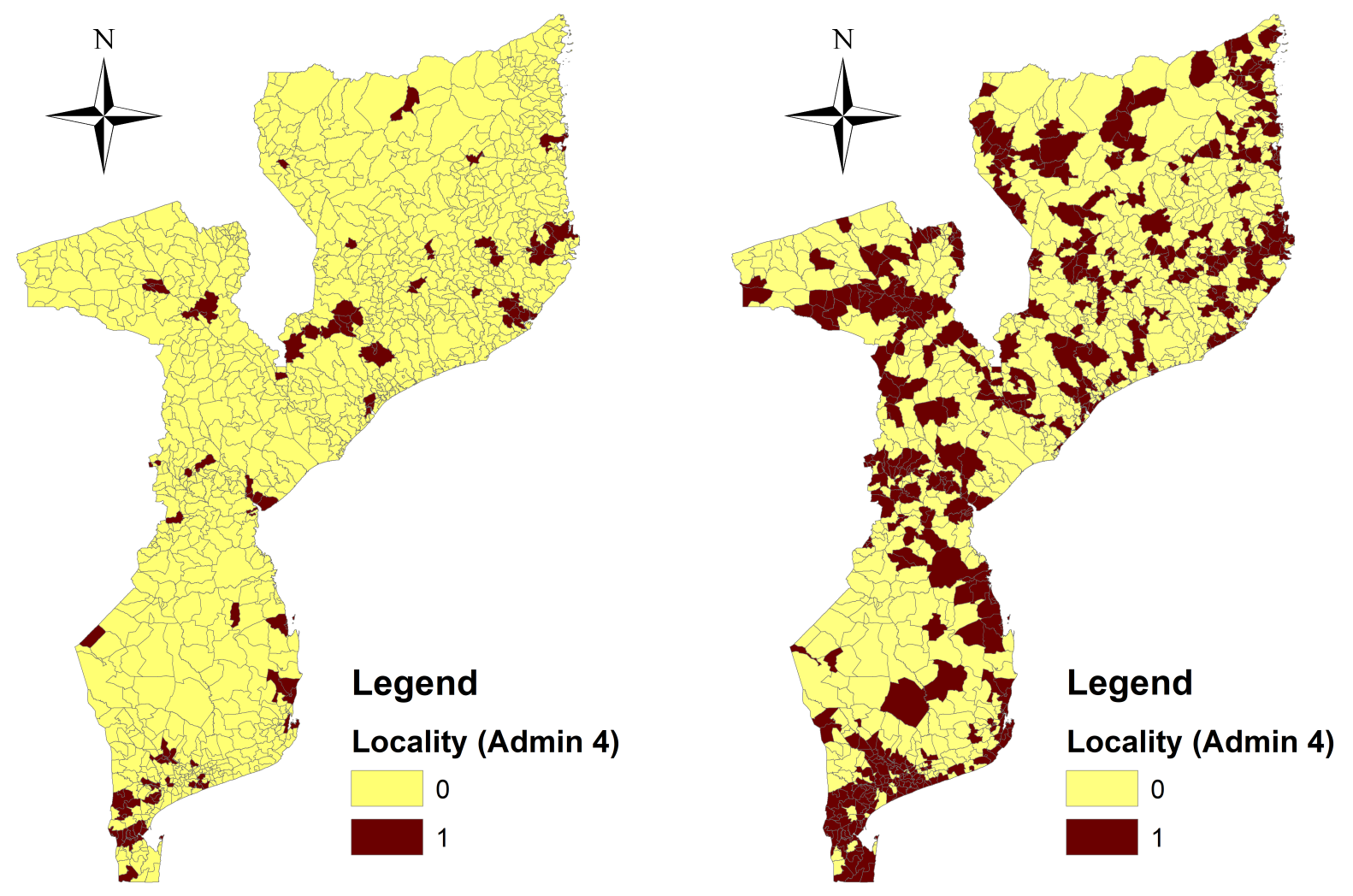

Figure 3: Panel A: Lit Localities in 1992 Panel B : Lit Localities in 2015

\footnotetext{
${ }^{16}$ The VIIRS imagery has replaced the DMSP-OLS measurements after 2013. Since these satellites provide measurements of different sensitivity, we follow $\mathrm{Li}, \mathrm{Li}, \mathrm{Xu}$, and $\mathrm{Wu}$ (2017) to make VIIRS values comparable to DMSP-OLS. in Appendix IV we cross-validate the luminosity data, showing that luminosity correlates strongly with survey data on household wealth, access to public goods, and education from the Demographic and Health Surveys (DHS) across thousands of villages within Sub-Saharan African countries and across Mozambican enumeration areas.
} 


\subsection{Other Data}

We used a plethora of additional data that we describe in detail in the Appendix. We compiled proxies of civil war intensity using data from Domingues et al. (2011), Robinson (2006), and the UCDP GED (Sundberg and Melander (2013)). 16\% percent of localities experienced a civil war event. We also digitized colonial-era information on the presence of cantinas, villages that were used during the colonial era by mostly Portuguese settlers to collect cash crops and ship them to the main ports. Around $58 \%$ of the localities hosted at least one cantina. Table 2 gives summary statistics at the locality level. ${ }^{17}$

\subsection{Correlates of Confirmed Hazardous Areas (CHA)}

To better understand the placement of landmines during the war of independence and the civil war, we investigated its correlates. We run linear probability, probits, and negative binomial ML models associating the likelihood (and the number) of CHAs with geographic and locational characteristics (e.g., proximity to roads, railroads, and borders), civil war intensity, and early development proxies (e.g., population density in 1980 and presence of cantinas in 1965). For brevity, we report and discuss the results in Appendix $V$. The analysis yields the following. First, in accordance with the historical narrative, contamination is high in localities close to the border with Zimbabwe (reflecting the minefields set up by FRELIMO, Zimbabwean rebels and the Rhodesian army during the initial phase of the civil war), Swaziland, and Tanzania (where the Portuguese planted large minefields to block FRELIMO's raids during the independence war). Second, the colonial transportation network was heavily mined. Third, landmine placement was, on average, higher in larger in terms of area and population localities. Fourth, contamination was higher in places that experienced more civil conflict.

\subsection{Correlates of Timing of Clearance}

We then examined the evolution of clearance, looking separately at the timing of the first and the last demining intervention.

Panel $A$ of Figure 4 plots the yearly share of localities that had their first demining intervention. By the end of 1994, when the first democratic elections took place, clearance operations had started in just $6.54 \%$ (56) of contaminated localities (855). By early 2000, the cumulative percentage (number) of localities where some clearing had taken place was $48.53 \%$ (415). It jumps to $89.12 \%$ in 2007 . Panel $B$ - Figure 4 depicts the yearly evolution of the share of localities that were fully cleared. At the end of 1994 , only $0.7 \%$ (6) of contaminated localities were cleared. The percentage (number) increases slightly to $5.61 \%$ (48) in 2000. Roughly half (442) of the localities were fully cleared by the end of 2007.

\footnotetext{
${ }^{17}$ In the Appendix III we tabulate the respective summary statistics for the localities for which we recover 1980 population (1,077 out of the 1,187 localities). There are no major differences between the two samples.
} 


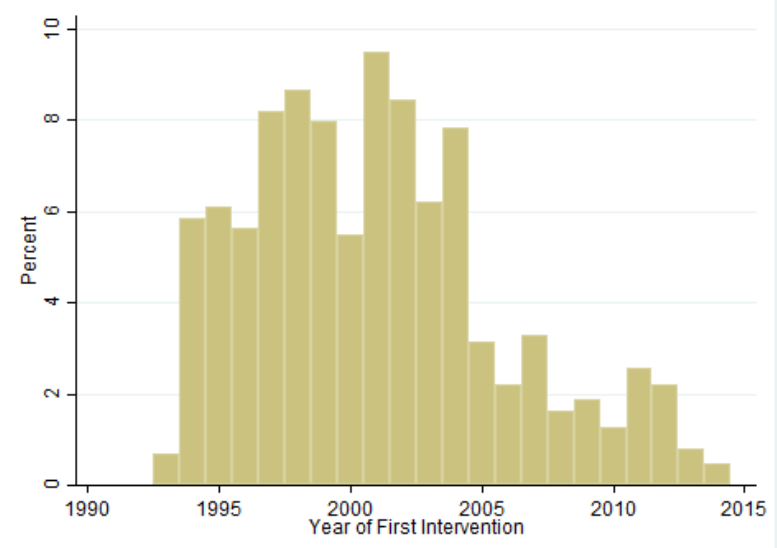

Panel A: First Intervention across Localities

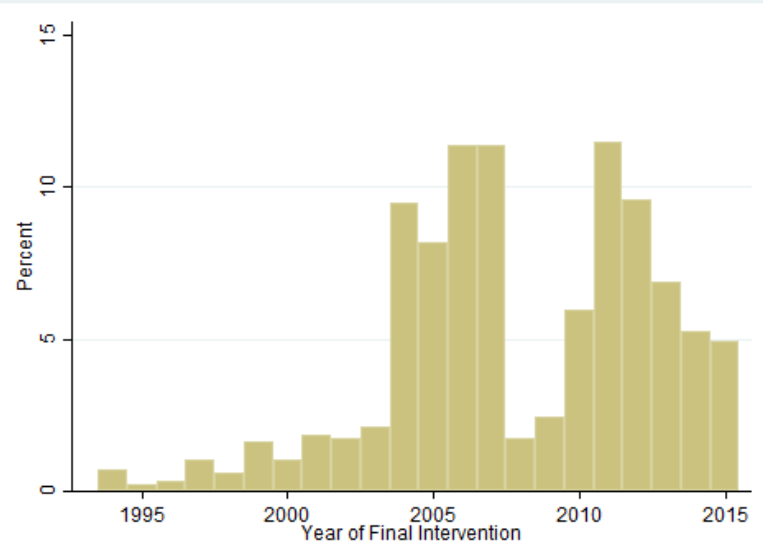

Panel B : Last Intervention across Localities

Figure 4: Distribution of the Timing of Intervention across Localities

$22 \%$ (191) of contaminated localities get cleared in the same year. The average (median) number of years to clear a locality is, however, 6.99 (6) with a standard deviation of 5.93. The difference between the timing of the first and last clearance is not because operations take years (on average a CHA is cleared in four months), but because there were several interventions in each locality. Due to the fragmented and very localized nature of demining and the errors of the initial surveys, demining operators had to go back and forth, visiting contaminated localities multiple times during the 1992 - 2015 period.

We then associated the years elapsed between 1992 and the year of the first and the last intervention with locality-specific features. In Appendix V we detail the analysis that yields the following: First, the timing of the initial intervention is related to only a few observable characteristics; the explanatory power of the model is low. In line with the historical narrative, early interventions took place in areas close to the border with Malawi, as one of the objectives was to bring back the one million refugees in this country. Landmine clearance started earlier in localities that experienced warfare during the civil war and in more densely populated ones. And while early reports indicate that clearance operations in the 1992 - 1994 period targeted some roads (e.g., RONCO's contract with UNOMOZ), localities with railroads or primary roads do not seem to be targeted earlier, as many roads and railroads were cleared in the 2000s. Second, when we examine the correlates of full clearance, we also find that the main correlates are proximity to the borders. Crucially, clearance of localities alongside the main transportation network or of more populated ones does not happen earlier.

The analysis suggests that the process of localities' clearance did not follow a systematic pattern; this reflects the lack-of-coordination, IND's limited capacity, the ad-hoc and short-term nature of clearance operations (as financially constrained NGOs were doing fund-raising for specific CHA at a time), the flaws of the 1994 and 2001 surveys, the big floods of 2000 - 2001, and the subsequent back and forth of the international community. 


\section{Landmine Clearance and Local Development}

In this section, we present the analysis of the local consequences of demining. Before proceeding with the results, it is important to stress that the uncovered correlations between clearance and luminosity do not necessarily identify causal effects. While the timing of landmine clearance does not seem to follow a systematic pattern, there are endogeneity-related concerns. First, obviously demining did not follow some strict randomization criterion and one cannot rule out that operators prioritized areas with high-growth potential (though our interviews and extensive sensitivity checks suggest otherwise). Second, spatial interdependencies are likely, as clearing a particular area from landmines may have positive or even negative (population relocation) spillover effects in connected regions. Last but not least, despite our efforts to collect and record all clearance interventions, measurement error is likely to be non-trivial.

\subsection{Panel Estimates}

The estimation approach looks at the coevolution of luminosity and clearance of CHAs, netting out locality-specific, time-invariant characteristics and allowing for province-specific time trends. The "difference-in-difference" specification takes the following form:

$$
y_{i, t}=\mu_{i}+\mu_{t, p}+\beta C L E A R_{i, t}+\eta_{i, t}
$$

$y_{i, t}$ reflects economic activity in locality $i$, reflected in light density at night, in year (period) $t$. We conduct the analysis at the yearly level and at the end of each of the three main periods of demining (1999, 2007, 2015) and in the beginning (1992).

To account for the non-linear nature of the dependent variable, we apply two transformations. First, we focus on the extensive margin of luminosity using a dummy variable that equals one if the locality is lit. Second, we use the log of light density augmented by a small number. ${ }^{18}$ We use two proxies of demining $\left[C L E A R_{i, t}\right]$. The first, Cleared Threats $s_{i, t}$, denotes the logarithm of one plus the cumulative number of cleared CHA. (We use the cumulative number of CHA, so positive coefficients imply increases in luminosity after clearance). The second is an indicator (Cleared i.t $_{\text {) }}$ that takes on the value of 0 while a locality is contaminated and becomes 1 the year it becomes landmine free and remains 1 thereafter; the variable equals zero for all localities that were never contaminated. The locality-specific constants, $\mu_{i}$, capture time-invariant, local characteristics that may affect development/urbanization and landmine clearance; for example proximity to borders, presence of cantinas, and topological features. The province-time constants, $\mu_{t, p}$, account for the idiosyncratic process of demining across the Mozambican regions, unobserved time trends, and also allows us to compare localities with broadly "similar" histories.

\footnotetext{
${ }^{18}$ We add half the minimum positive value in the data; $\ln \left(0.0001+\right.$ light $\left./ \mathrm{km}^{2}\right)$.
} 
Table 3 reports the panel estimates. Standard errors are clustered at the admin-2 (district) level, as this accounts both for serial correlation and spatial (within-district) interdependencies. ${ }^{19}$ The table also reports [in brackets] the standardized "beta" coefficients that reflect the change in the outcome variable to a one-standard-deviation change of the explanatory variable. Columns (1)-(4) exploit annual variation, while columns (5)-(8) give demining-period estimates.

Across all permutations, the CHA clearance proxy (Cleared Threats T $_{i, t}$ and Clearedi.t) enters with a significantly positive estimate. This implies that development-urbanization, as reflected in luminosity, increases significantly in localities that are partially or fully cleared compared to localities that have not been (fully) cleared and localities without any contamination. The standardized "beta" coefficient in column (1) implies that a one-standard deviation increase in the number of cleared CHA increases $\log$ luminosity by 0.072 standard deviations. In columns (3) and (4) we examine how the extensive margin of luminosity reacts to a decline or the elimination of CHAs. Clearing a locality from all contaminated hazardous areas increases the likelihood of the locality being lit by roughly $4 \%$; this estimate should be compared with an average value of the locality being lit of $9.7 \%$ in 1992 .

In columns (5)-(8) we examine the association between light density and landmine clearance over the medium run (7 year periods). A benefit of these specifications is the reduction in measurement error on the exact timing of clearance operations. The estimated magnitudes are uniformly larger suggesting that demining's payoffs materialize over time. Specification (8) suggests that the likelihood of a locality being lit increases by around 8 percentage points when fully cleared. To gauge the economic significance of the estimate, we estimated the elasticity between light density and development proxies across Mozambican localities using the 2009 and 2011 Demographic and Health Surveys [see Appendix IV]. Differences in education between lit and unlit localities are considerable, 1.5 years on average. DHS tabulations also suggest that the difference in the quintile of the DHS composite wealth index (median 3) between lit and unlit localities is 0.9 .

\subsection{Long-Run Differences (1992 - 2015)}

We also adopted a long-run (2015 - 1992) difference specification (variant of equation (1)):

$$
\Delta y_{i, 2015-1992}=\mu_{p}+\beta \Delta C L E A R_{i, 2015-1992}+X_{i, \text { initial }}^{\prime} \Phi+\Delta \eta_{i, 2015-1992 .}
$$

The merit of this specification is that we can account for conditions at the end of the war in 1992. These initial conditions may affect the dynamics of luminosity and clearance. The vector of initial characteristics, $X_{i, \text { initial }}^{\prime}$, includes luminosity in 1992 (that captures potential convergence dynamics), $\log ($ area $), \log$ (population in 1980), indicators for the different features of the 1973 transportation network, an indicator of civil war violence, and an indicator for cantinas. The province-specific

\footnotetext{
${ }^{19}$ Clustering at the coarser province level or applying Conley's correction to account for spatial interdependencies yield smaller standard errors.
} 
constants, $\mu_{p}$, further account for the differential progress of landmine clearance and other hard-toobserve features shaping growth dynamics across provinces.

Table 4 reports the estimates. The dependent variable in columns (1)-(4) is the change in log luminosity between 1992 and 2015 and in (5)-(8) is the difference of the locality being lit. The latter takes three values; -1 for localities that were lit in 1992 and unlit in 2015, 0 for those observed either lit or unlit in both years, and 1 for localities which were unlit in 1992 and lit in 2015. The unconditional specification estimates in (1) and (2) on changes in clearance are positive and highly significant. Accounting for differences in initial conditions in (3)-(4) does not move much the coefficients on clearance. This is not because the additional variables are insignificant correlates of post-conflict development. The model's explanatory power improves substantially with the adjusted $R^{2}$ increasing by roughly $35-40$ percentage points. ${ }^{20}$

In spite of the inclusion of the rich set of significant controls, the coefficients of the landmine clearance variables retain their significance. The standardized coefficient in column (4) is 0.075 suggesting that cleared localities (as opposed to not-contaminated ones) enjoy a boost in economic activity comparable to that of being one of the few localities endowed with a colonial railroad (about $13 \%$ of the sample). The patterns in columns (5)-(8) where the dependent variable is the change in the lit indicator are similar. While pre-war traits correlate strongly with subsequent regional growth, they do not change the strong association between clearing and long-run growth. The estimate on

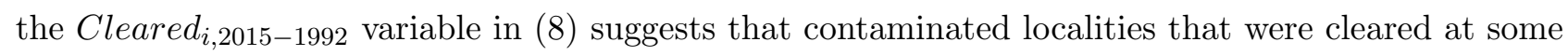
point between 1992 and 2015 are 11\% more (less) likely to going from unlit (lit) in 1992 to lit (unlit) in 2015 compared to localities without any contamination.

\subsection{Further Evidence and Sensitivity Analysis}

We perturbed the specifications across various dimensions to examine robustness and better understand the observed associations. We discuss our findings briefly below and in detail in Appendix VI.

\subsubsection{Further Evidence}

As a starting point, we examined the association between CHA clearance and population. The difference specifications (over the 1992 - 2007 period, as the 2017 census data have not been processed yet by the statistical agency) reveal a positive, but in general small and not always significant association. Sadly, as we lack population data at the end of the civil war in 1992, we cannot quantify how demining facilitated the return of internally and externally displaced Mozambicans.

\footnotetext{
${ }^{20}$ Localities endowed with the colonial transportation infrastructure have experienced larger increases in luminosity; more populous localities as of 1980 and localities serving as local trade hubs before independence have also grown faster. The civil war dummy is also highly significant pointing to post-conflict catch-up dynamics. There is also evidence of (conditional) convergence, with relatively underdeveloped localities, experiencing faster growth.
} 
We then examined the role of landmine clearance on the building of new roads and improvements of the colonial transportation network. Clearance is significantly associated with improvements in the colonial-era road-railroad network, revealing a plausible mechanism at play. Demining in unrelated to new road construction.

\subsubsection{Robustness Checks}

In Appendix VI we show that the results are robust to a plethora of sensitivity checks. First, we controlled for new road construction and improvements of the old transportation network, as landmine clearance is related to road improvements. Second, we dropped Maputo and also Beira and Nacala, both because luminosity is extremely high and because contamination was relatively low in big cities. Third, we restrict estimation to the less developed Northern provinces, as the HALO Trust data seem less noisy. Fourth, we stopped in 2013 (rather than 2015) to account for the change in the satellite technology recording luminosity. The results are quite stable. Fifth, we estimated dynamic panel specifications. Due to inertia in luminosity, the "long-run" effect of clearance is larger than the yearly estimates and quite close to the period estimates. Sixth, we examined whether luminosity increases as early as the first demining operation in the locality when in fact the last intervention is completed. Economic activity picks up when a locality is fully cleared. ${ }^{21}$ Seventh, we looked only at contaminated localities. Standard errors increase, but the estimate on CHA clearance retains significance. Eighth, instead of deriving the locality estimates of landmine contamination based on the number of demining interventions we used the number of CHA. Results are similar. Ninth, we aggregated the data (luminosity and clearance) across admin-3 units, as this reduces measurement error and may account for local spillovers finding similar coefficients. Tenth, we associated luminosity with the log of one plus the number of cleared confirmed hazardous areas (CHA) and the log of one plus the number of suspected hazardous areas (SHA) that surveyors declared as "cancelled", as they were based on false information and/or misreporting. The clearance of CHA continues to enter with a significantly positive coefficient, while luminosity does not respond to the cancellation of erroneously recorded SHA.

\subsection{Heterogeneity}

The specifications reveal a significant boost of economic activity after clearance operations. But this does not necessarily imply that landmine clearing is always and equally beneficial. Exploring heterogeneity may give provide clues into what is driving the link between demining and local economic activity.

First, we examined heterogeneity with respect to intervention characteristics. We used the CHA report coordinates to classify them into 7 non-mutually-exclusive categories based on proximity to

\footnotetext{
${ }^{21}$ This finding shows that concurrent to demining development projects or the presence of deminers are unlikely to be driving the observed positive association between demining and regional development.
} 
roads and railroads (using a distance cutoff of 100 meters in the 1973 network), navigable rivers (cutoff of 100 meters), borders (cutoff 1 kilometer), villages and towns (radius of 1 kilometer), electricity pylons-grid (100 meters radius), cantinas (radius of 1 kilometer), and points of civil war violence (radius of 1 kilometer). ${ }^{22}$ Table 5 reports the estimates. On the one hand, reducing the number of contaminated areas along roads-railroads and clearing areas around villages and towns, espcially the ones with cantinas is associated with significant increases in luminosity. On the other hand, removal of landmines in remote, rural areas (the residual category) does not seem to lead to increases in luminosity. Likewise, clearance of electricity pylons that are mostly in low population density areas or river banks do not lead to increases in development-urbanization. The removal of landmines in border areas is -if anything- negatively related to luminosity. The most probable explanation is the considerable relocation of population in the early post-conflict period from refugee camps along the borders with Malawi and Zimbabwe to the refugees' homelands.

Second, we explored heterogeneity with respect to a locality's features. We estimated separately equation (1) for localities connected and non-connected to the colonial transportation system (so as to also accounts for differential time trends in the two sets of localities). The correlation between luminosity and CHA clearance is positive and highly significant for connected localities (888), while it is close to zero and statistically insignificant for non-connected ones (299). Panel A of Figure 5 gives a graphical illustration (of the estimates reported in Appendix VI). When we look within connected localities, we find that the landmine clearance luminosity correlation is especially strong for localities with paved roads and crossed by railways rather than trails and unpaved roads (results reported in Appendix VI for brevity). We also split the sample into quintiles using the pre-civil-war population density and run separate specifications for each set of localities. As shown in Panel $B$ of Figure 5, the impact of landmine clearance is more pronounced in densely populated localities. ${ }^{23}$

The analysis reveals economically meaningful heterogeneity. Clearing hazardous areas along the transportation network, villages of commercial importance and more densely populated communities generate larger economic payoffs than interventions in remote, rural, border places that do not seem to map into significant increases in luminosity.

These patterns suggest that clearing the transportation infrastructure is likely to not only benefit

\footnotetext{
${ }^{22} 16 \%$ of all CHAs were found along the transportation network; $14 \%$ placed within a kilometer from villages' and towns' centroids; $8 \%$ are found along border areas and a similar percentage was traced close to cantinas; $10 \%$ were found either in areas that experienced civil war violence and along the electricity grid. $61 \%$ of CHAs, which are not sufficiently close to any of the aforementioned features, are in the residual category.

As there is subjectivity on the radii and distance cutoffs, we have experimented with alternative values. For example, we increased cutoffs by $100 \%$ and $200 \%$ or decreased them by $50 \%$. As we show in Appendix VI, the patterns are similar.

${ }^{23}$ In the Appendix VI we report various sensitivity checks on the heterogeneous association between luminosity and landmine clearance. We also examined heterogeneity with respect to intervention characteristics using information from the demining reports. Specifically, for 4,582 out of the 7,423 interventions we have information on the type of contamination. So, we classified operations into 10 non-mutually exclusive categories. The largest categories concern contamination of electricity pylons $(13 \%)$, footpaths $(12 \%)$, roads and railroads $(11 \%)$, farms $(10 \%)$, residential areas $(10 \%)$ and areas of military importance, typically public buildings (schools, townhouse, clinics). The estimates although less precisely estimated (due to the missing classification for roughly $40 \%$ of the clearance operations) are broadly consistent with the patterns found in Table 5.
} 


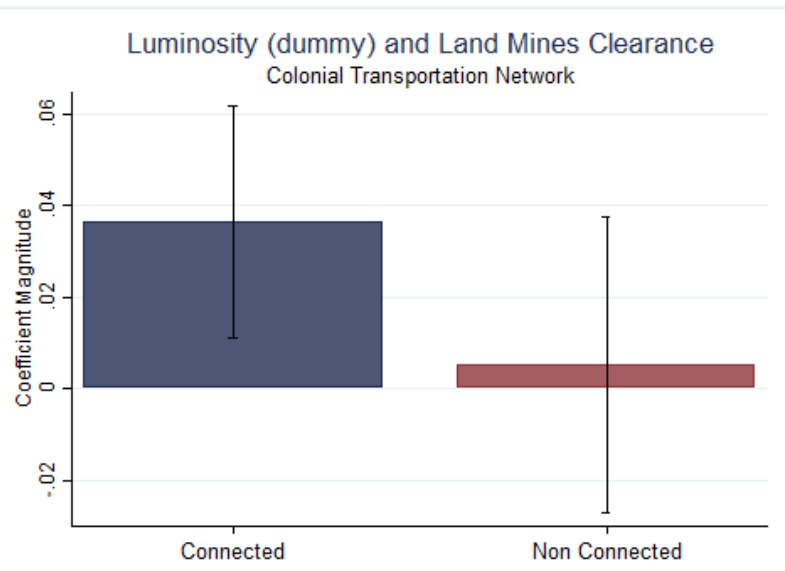

Panel A: Connected vs Non Connected

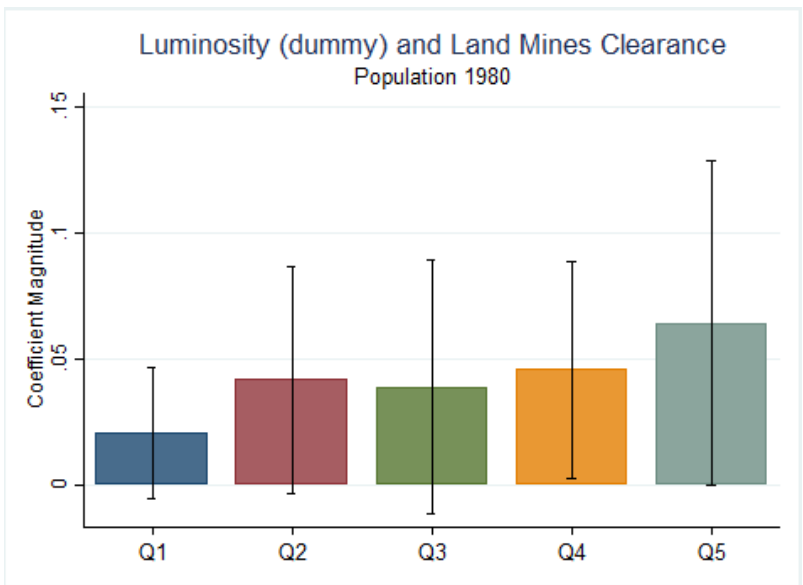

Panel B:Population Quintiles

Figure 5: Heterogeneity on Locality Characteristics

the locality where this segment lies, but may also increase the usefulness of the transportation network overall. We formally explore this possibility below employing a framework designed to assess spillovers.

\section{Landmines and Aggregate Development. A Market- Access Ap- proach}

We now turn to the examination of the economy-wide effects of landmine clearance on development. We start by briefly discussing the theoretical underpinnings of the empirical approach and the discuss the construction of the "market-access" measures that requires the calculation of bilateral (localitypair) transportation costs factoring in landmine contamination and road-railroad quality. We then report the results. Appendix VII provides an in-depth discussion of the underlying theoretical framework, the construction of the market access measures, and the sensitivity analysis.

\subsection{Theoretical Foundations ${ }^{24}$}

Our conceptual framework follows Donaldson and Hornbeck (2016) and other recent works (e.g., Donaldson (2018), Alder (2017), Pérez-Cervantes (2014)) that, building on Eaton and Kortum (2002), develop Ricardian general equilibrium models of inter-district trade and spatial development. This setup is appropriate for agricultural economies, like that of Mozambique. where the share of employment in agriculture exceeded $80 \%$ in the 1990 s, while nowadays hovers around $70 \%$.

Donaldson and Hornbeck (2016), specifically, derive a "reduced-form" log-linear relationship from this set of models linking aggregate welfare (income) to a locality's "market access" (see also Alder

\footnotetext{
${ }^{24}$ Donaldson (2015) provides an eloquent review of this body of research. Costinot and Rodriguez-Clare (2014) provide an overview of quantitative works on trade across and within countries.
} 
$(2017))$.

$$
\ln \left(Y_{d}\right)=\kappa+\alpha_{o}+\lambda \ln \left(M A_{o}\right)
$$

where a locality's $o$ "market access" $\left[M A_{o}\right]$ is:

$$
M A_{o} \approx \sum_{d=1}^{D} \tau_{o, d}^{-\theta} N_{d}\left(Y_{d}\right)
$$

where $N_{d}$ and $Y_{d}$ reflect total population and total output of all but-the-origin locality and $\alpha_{o}$ are locality fixed effects, capturing technology, endowments, and other local features.

Market access $\left(M A_{o}\right)$ for a given locality is the sum of the income (population) of all other localities, discounted by bilateral transportation $\operatorname{costs}\left(\tau_{o, d}>1\right)$, scaled by a "trade elasticity" parameter $(\theta)$. The latter theoretically approximates localities' comparative advantage, with lower (higher) values pointing to stronger (weaker) comparative advantage.

\subsection{Market Access across Mozambican Localities}

Constructing a locality's market access requires estimating bilateral costs across all locality-pairs $\left(\tau_{o, d}\right)$ and then scaling them with an appropriate trade elasticity $(\theta)$.

\subsubsection{Bilateral Transportation Costs}

The construction of transportation costs entails four steps. First, we create the transportation network that consists of railroads, paved roads, unpaved roads, trails, and navigable rivers. We also allow for the possibility of straight-line connection on foot (walking) among localities' centroids (Donaldson and Hornbeck (2016)).

Second, we parameterize the (relative) cost of the network's elements. We try to tie our hands following earlier and parallel works (Donaldson (2018), Donaldson and Hornbeck (2016), Alder (2017), and Jedwab and Storeygard (2018)). The most efficient (trade) technology is the railway, whose cost is normalized to 1 . The (relative) cost of paved roads is 2 and of unpaved roads is 4 . The relative costs of trails -that typically connect roads to villages and small towns- is 10 , as even today they are in poor conditions. For walking, we assign a relative cost of 20. The last component of the network are navigable rivers; given their tiny role for local trade, we assign a relative cost of 15 . The precise values of the cost parameters are not particularly important; what really matters are the relative costs (of say utilizing a paved road instead of a trail). We return to this issue in the Sensitivity Analysis.

Third, regarding the role of landmines, we impose that the presence of a CHA within 100 meters of a road/railroad/trail and navigable river is blocking the usage of the respective segment. This accords with the clearance reports, the Mozambique-wide surveys, our interviews with deminers, and 


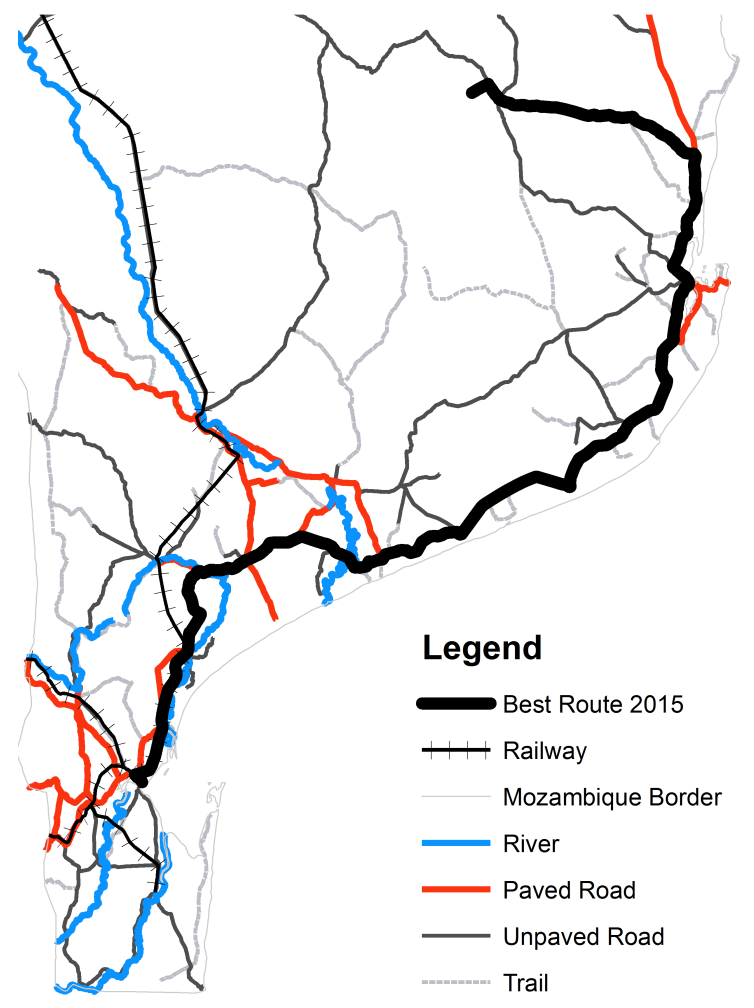

Panel A: Optimal Route 2015

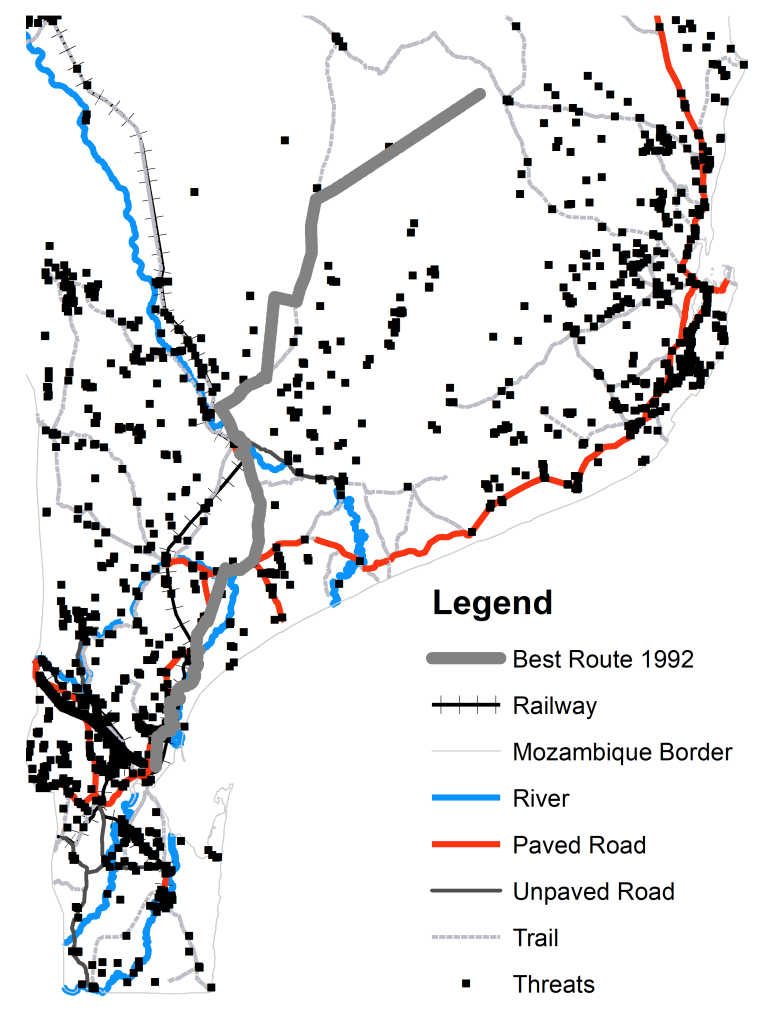

Panel B: Optimal Route 1992

Figure 6: Least-Cost Route according to Dijkstra's Algorithm

the reports of various specialized organizations (Landmine Monitor (2015), ICRC (2002)). In the Sensitivity analysis, we experiment with different cutoffs and even relaxed the blocking assumption.

Fourth, we approximate the time required to travel from each locality to all other localities using Dijkstra's algorithm. This algorithm -that is similar to the GoogleMaps application one- solves for the lowest-cost path between any two localities' centroids. We compute the shortest paths in 1992 and at the end of the three phases of the demining process.

Figure 6 illustrates the algorithm-derived shortest route between Maputo and Funhalouro, a locality $600 \mathrm{~km}$ north of the country's capital. Panel $A$ shows the optimal path in the end of 2015 . As all hazardous areas have been cleared, the algorithm is employing the most efficient network elements, yielding an identical to the "google maps application" path for a 9-hour journey. The route for 1992, illustrated in Panel $B$ of Figure 6 is quite different. As the main primary road (highway $N 1$, connecting Maputo to the Centre alongside the Indian Ocean) and the secondary road linking Funhalouro to $N 1$ are blocked by dozens of minefields, the algorithm uses the non-contaminated parts of the transportation network relying often on unpaved roads and trails; this results in a 3.5-fold cost increase. 


\subsubsection{Trade Elasticity Parameterization}

The literature has produced a range of trade elasticity $(\theta)$ estimates (from 2.5 to 10 ) depending on the context (the type of trade, manufacturing, agriculture, etc.). As a benchmark, we follow Donaldson (2018), Donaldson and Hornbeck (2016) and Alder (2017) and use a value of 3.88. This estimate is close to the midpoint $(2.79-4.46)$ of the estimates that Simonovska and Waugh $(2014 \mathrm{a}, \mathrm{b})$ produce in their careful estimation of the trade elasticity in comparative advantage models. It is also similar to the one that Jedwab and Storeygard (2017) use in their analysis of the impact of roads on Africa's urbanization. Below, we examine the sensitivity of our results to alternative parameterizations.

\subsection{Market Access Measures}

We construct two "market access" measures. First, we estimate market access proxying aggregate demand (total output) in the destination locality with the sum of lights, $Y_{d, t}$. This approach is similar to Alder (2017), who also uses satellite images of light density to proxy local output in Indian localities; it is also conceptually similar to Donaldson and Hornbeck (2016), who use total property value across US counties during late 19th century. Second, we use total population $\left(N_{d, t}\right)$ to proxy for aggregate demand, an approach that is similar to Donaldson and Hornbeck (2016) and Jedwab and Storeygard (2018). We construct the market access measures in the beginning of each of the main periods of demining $(1992,1999$, and 2007) and in 2015 when the country was declared "landmine free". For the market access in 1992 we use the 1973 network and the census population of 1980 (and luminosity in 1992). For the 1999 market access measure we use the 1998 transportation network and the population census of 1997. For the 2007 market access, we use the infrastructure network in 2003 and the census population of 2007. For the market access in 2015 we use the transportation infrastructure of 2011 with the population of 2007, as data from the very recent Census are not available yet. Table 2 reports summary statistics.

Figures $7 a-b$ plot changes in the two market access measures over the period $1992-2015$, where darker colors indicate larger increases in market access. The correlation of changes in the two proxies of market access is $0.50 .^{25}$ There is considerable variation in changes in "market access" across Mozambique, even when one looks within provinces. Province constants explain just $19 \%$ and $5 \%$ of the overall variability. Even when we add admin-2 constants, there is still sizeable variability in "market access" as the $R^{2}$ is far from one, 0.57 and 0.32 with the luminosity and the population based "market access", respectively. We also calculate various modified "market access" measures that we discuss below.

\footnotetext{
${ }^{25}$ The mean (median) of long-run changes in the luminosity-based market access measure is 5.55 (5.53) and the standard deviation is 2.12. The average (median) of changes in the population-based market access measure is 2.90 (2.8) and the standard deviation 1.26 .
} 


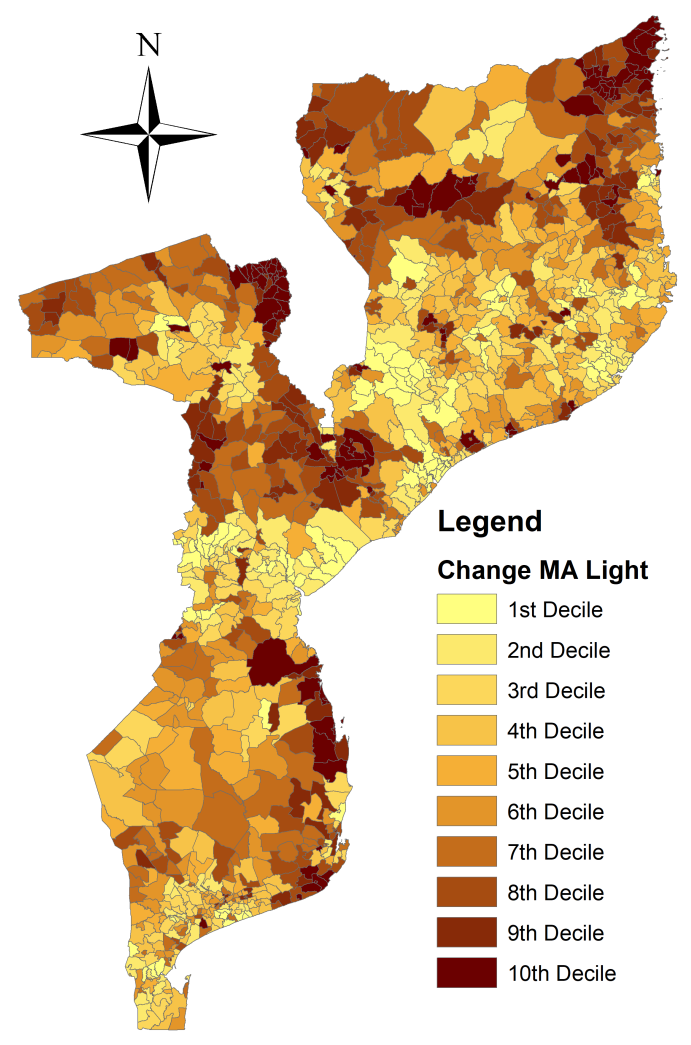

Panel A: Change in Log MA1 (Luminosity)

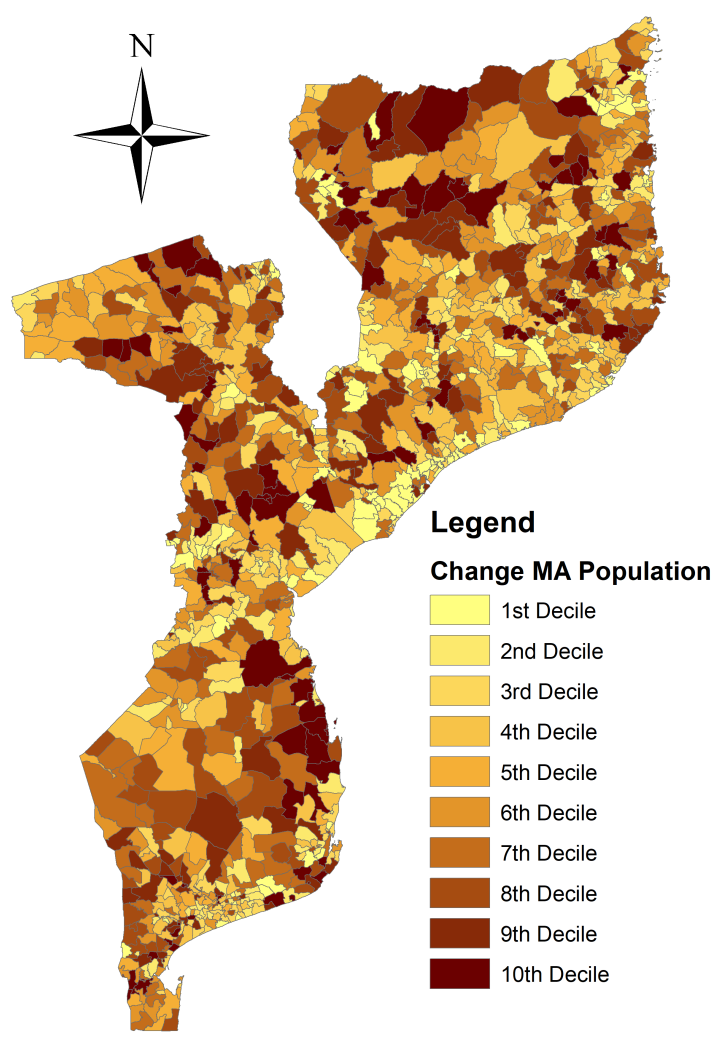

Panel B: Change in Log MA2 (Population)

Figure 7: Change in Contemporaneous Market Access

\subsection{Results}

\subsubsection{Empirical Specification}

We estimate the relationship between a locality's level of development, as reflected in luminosity $\left(y_{i, t}\right)$ and its market access $\left(M A_{i, t}\right)$, running variants of the following equation:

$$
y_{i, t}=\mu_{i}+\mu_{t, p}+\lambda \ln \left[M A_{i, t}\right]+\zeta_{i, t}
$$

Similarly to equation (1), $\mu_{i}$ and $\mu_{t, p}$ are locality specific constants and province-specific time effects, respectively. The coefficient on the market access $\left(M A_{i, t}\right)$ reflects both the direct and indirect effects on local economic activity of improved accessibility, due to landmine clearance and road-railroad improvements and extensions. ${ }^{26}$

\footnotetext{
${ }^{26}$ As before, we also estimated "difference a difference" version of this specification, examining the association between changes in luminosity and changes in market access over the $2015-1992$, as this allows accounting for initial (at the end of the war) features. $\left[\Delta y_{i, 2015-1992}=\mu_{p}+\lambda \Delta \ln M A_{i, 2015-1992}+X_{i, \text { initial }}^{\prime} \Phi+\Delta \eta_{i, 2015-1992}\right]$. As the results are similar, we report them in Appendix VII.
} 


\subsubsection{Baseline Luminosity - Market Access Elasticity}

Table 6 reports the baseline estimates of the luminosity - "market access" association. The elasticity with the luminosity-based market-access measure is 0.29 in column (1); with the population-based "market access" measure in (3) the elasticity is 0.25 . The linear probability model estimates in (2) and (4) suggest that a one-standard deviation increase in market access increases the likelihood that the locality is lit by $5 \%-6 \%$. Although the process of landmine clearance is only weakly related to observables, one cannot entirely rule out that (at least in some instances) the demining operators prioritized localities with high growth potential. To partly account for this concern, in columns (5)-(8) we augment the specification with the log number of cleared CHA in a given locality at the end of each period. This also allows to partial out the direct "effect" of landmine clearance documented above.

Three patterns emerge. First, the luminosity- "market access" elasticity continues to be highly significant, revealing the presence of spillovers. Second, the coefficient on landmine clearance also retains significance, being similar to the one in Table 3 that solely examined the "local" impact of demining. Local and spillover effects seem to be at play. Third, the comparison of the standardized coefficients [in brackets] of the market access and the CHA clearance variable shows that spillovers are considerable; they are twice as large as the "direct" effect with the luminosity-based market access proxy (in (5) and (6)) and equally large to the "local" effects with the population-based market access (in $(7)-(8))$.

\subsubsection{Luminosity - Market Access Elasticity in Non-Contaminated Localities}

A sharper way to isolate spillovers is looking at localities without any landmine contamination. For these 332 localities (28\% of the sample) changes in "market access" are driven by demining operations or other developments (new roads, improvements of old roads) in other interconnected localities. Another benefit of looking at these localities (that in the difference-in-difference specifications were part of the "control" group) is that endogeneity concerns regarding the timing of clearance operations are muted (as these localities saw no demining). These localities are somewhat smaller, less densely populated, and less likely to have a primary road or railroad, as compared to contaminated ones. Table 7 reports the results. The coefficient on log market access continues to be statistically significant across all perturbations. The estimates are similar to the full-sample ones. A $10 \%$ increase in "market access" increases luminosity by approximately $2.7 \%$ and the likelihood that the locality will be lit by $3.2 \%$. The standardized coefficient is $0.2-0.3$, further illustrating the economic significance of spillovers.

These results show that the market access effects of CHA clearance operate above and beyond the local effect of demining. The existence of such relationship in non-contaminated by landmines suggests strong general equilibrium effects of clearance on spatial development, driven by the evolving accessibility of the transportation network. 


\subsubsection{Fixing Initial Conditions}

Transportation costs and hence localities' market access changes both because of landmine clearance and because of new road construction and improvements on the old transportation network. "Market access" also reflects changes in population/development across localities over time. As we have shown earlier, landmine clearance is associated with development-urbanization (as reflected in luminosity), but also with improvements in the old transportation network and to a lesser extent with population swings.

To further isolate the impact of landmine clearance, we recalculated the two market access proxies (based on luminosity and on population), fixing the transportation network to the one left by the Portuguese in 1973 and holding all localities' luminosity (population) fixed in its 1992 (1980) level. Figures $8 a-b$ plot the long-run changes of the "market access" measures that fix both population and the road-railroad network to the pre-clearance ones. These market access measures net out any swings in population and any new road-railroad development, effectively capturing the role of landmine clearance on the accessibility of localities via the pre-independence transportation network. The two measures are strongly correlated (0.77). But, the correlation of the changes in the "market access" measures that only use initial conditions with the analogous ones that also reflect population movements and new road development (illustrated in Figures 7 ) is far from perfect, around $0.45 .{ }^{27}$

Table 8 reports the analysis that associates luminosity with the "market access" measures that impose the pre-clearance transportation network (1973), population (1980 Census), and luminosity (1992). We continue controlling for the direct effect of clearance. The elasticity ("beta" coefficient) on the luminosity-based market access measure is $0.26(0.2)$. The linear probability model estimate (in (2)) is 0.025 implying that a one standard deviation increase in market access (around 1.2) is associated with an 3 percentage point rise of the likelihood that the locality will be lit. The coefficient on the market access proxy, based on the 1973 network and population in 1980, is also highly significant (in (3)-(4)). The log number of cleared hazardous areas that captures the direct role of clearance continues to enter with a highly significant estimate. In columns (5)-(8) we control for new roads-railroads and improvements in the old transportation network. While the improvement of roads-railroads is a significant correlate of local development, this does not affect the market access coefficient; this is to be expected, as by fixing initial conditions, the market access measures only reflect the fall in transportation costs related to CHA clearance of at-independence network.

\subsubsection{Further Evidence and Robustness}

We performed a battery of sensitivity checks that we report in detail in Appendix VII. Here we briefly comment on them. First, we used alternative values for the trade elasticity $(\theta)$ that quantifies the role

\footnotetext{
${ }^{27}$ The mean (median) of long-run changes in the luminosity-based market access measure is $1.20(0.82)$ and the standard deviation is 1.26 . The average (median) of changes in the population-based market access measure is $0.52(0.20)$ and the standard deviation 0.82 .
} 


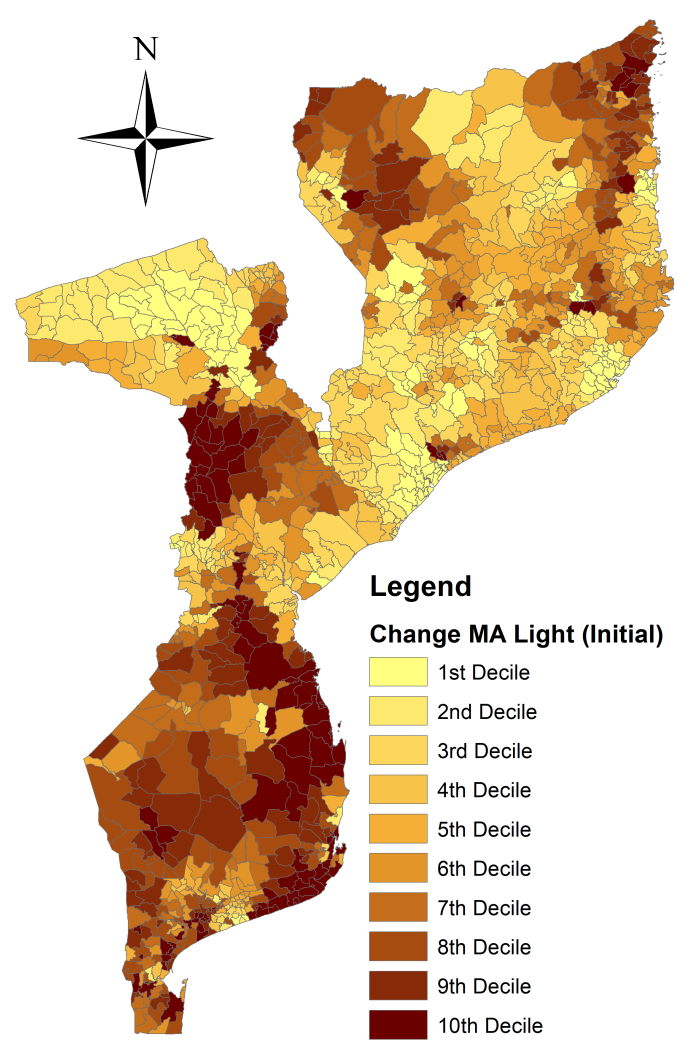

Panel A: Change in Log MA1 (Luminosity) Pre-clearance Network-Population

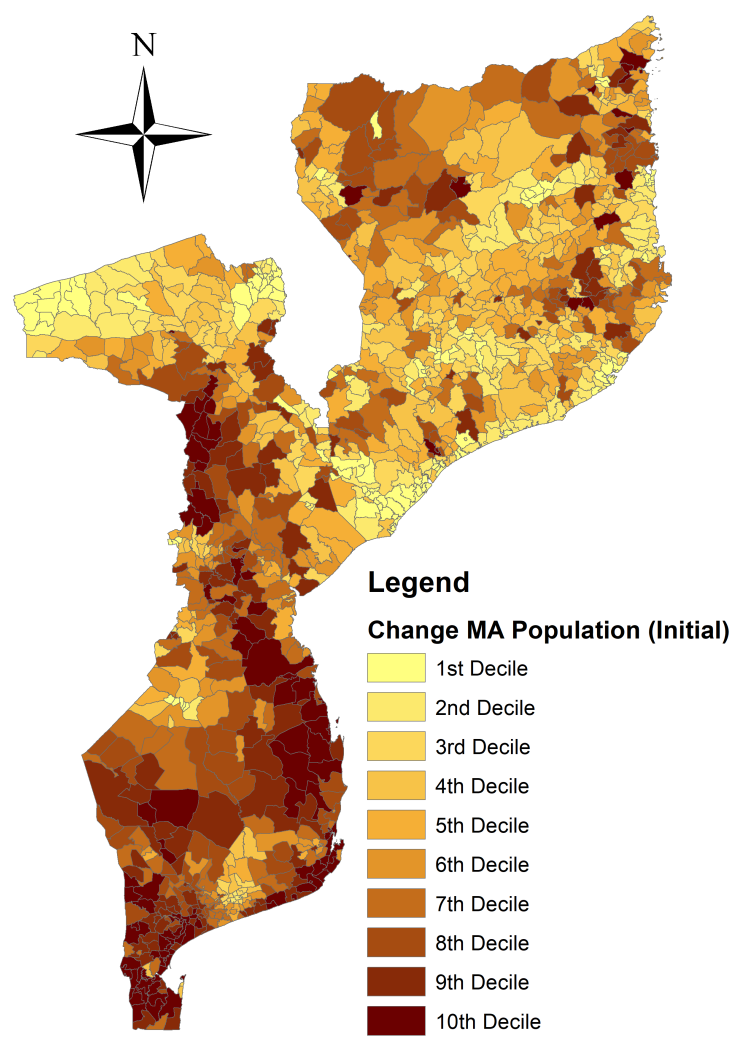

Panel B: Change in Log MA2 (Population) Pre-clearance Network-Population

\section{Figure 8: Change in Market Access. Initial Conditions}

of transportation costs. We experiment with both the low (2.7) and the high-end (5.23) estimates of Simonovska and Waugh (2014a,b) regarding agriculture-based Ricardian models of trade. We even tried higher values. The results are quite robust Second, we associated luminosity with transportation costs using a simple measure of locality's connectivity to all others taking the shortest path. By not taking into account market size (population or luminosity), we isolate the impact of landmine clearance from population-income. There is a strong negative association between transportation distance and development, reassuring that the estimates do not reflect the particular parameterization of the market access measure or the underlying theory-imposed structure. Third, we experiment with Harris' (1954) "market potential" measure (that equals $\sum_{d=1}^{D} \tau_{o, d}^{-1} N_{d}$ ) that imposes a trade elasticity of 1 . The luminosity - market potential association retains significance. Fourth, given the importance of Maputo, Beira, and Nampula-Nacala for Southern, Central, and Northern Mozambican trade with neighboring countries we inflated the population/luminosity of the port cities adding the values of Johannesburg (South Africa), Harare (Zimbabwe), and Malawi, respectively. The estimates are similar. Fifth, we examined robustness to alternative parameterization of transportation costs. Among other tests, we 
used the exact parametrization of Jedwab and Storeygard (2017). ${ }^{28}$ The results remain similar. Sixth, we dropped railways, as their role for intra-country commerce is limited, finding similar estimates. Seventh, we relaxed the assumption that mines block usage of affected transportation, assuming instead higher passage costs. Results remain intact. Eighth, we used perturbed market access measures that exclude adjacent localities, as this isolates market access changes from clearance operations far from the locality. The market access are only slightly attenuated and remain statistically significant. Finally, we estimated the market access specification in long-run differences, as this allows us to control for pre-clearance features (e.g., paved and unpaved roads, cantinas, civil war intensity). The luminosity - market access elasticity continues to be highly significant.

\section{Counterfactual Policy Simulations}

\subsection{A Mozambique without Demining}

What would have been Mozambique's aggregate economic activity in 2015 had the international community and the government left the problem of landmine contamination entirely unresolved? We address this (undoubtedly extreme) scenario estimating a simple policy counterfactual simulation that approximates the economy-wide impact of clearance. The counterfactual (that follows Donaldson and Hornbeck (2016)) works as follows. First, we calculate locality to locality lowest cost path connections with landmines (i.e., without any CHA clearance) imposing the 1973 transportation network. Second, we estimate two counterfactual (luminosity-based) market access statistics. The first assumes that landmines presence does not alter the actual distribution of luminosity; the second assigns to each locality its share in 1992 multiplied with the total level of luminosity in 2015. Third, we calculate the difference between the observed market access in 2015 (when the country was "landmine free") and the counterfactual measures that approximate localities' market access in the absence of any clearance. We then sum the (exponent of the) differences in realized and counterfactual market access across all localities multiplied by the baseline luminosity-market access elasticity (0.25). This sum approximates the aggregate (integrated over all localities) effects of CHA clearance. ${ }^{29}$

Table 10 reports the comparison of realized market access with the two counterfactuals. The counterfactual that uses actual luminosity growth suggests that luminosity would have been $58.7 \%$ lower in absence of clearance. The counterfactual that imposes the 1992 distribution of luminosity suggests that Mozambique's luminosity in the absence of any clearance in 2015 would have been $70.4 \%$ lower than what actually was. Given a GDP - luminosity elasticity of around $0.25-0.35$ (Henderson, Storeygard, and Weil (2012), see also Appendix IV) these counterfactual exercises imply

\footnotetext{
${ }^{28}$ The parametrization of Jedwab and Storeygard (2017) are 1 for highways, 1.33 for paved roads and railroads, 2 for unpaved roads, 6.66 for trails (earthen roads), and 13.33 for walking in places with no roads. This parameterization is close to ours, the main difference being that railroads are costlier than primary paved roads.

${ }^{29}$ Following Donaldson and Hornbeck (2016), we compute the percentage decling in luminosity as $\sum((\exp (\hat{\beta} *(\log$ MA $\left(f_{t}-\log\right.$ MA act $\left.\left.\left.t\right)\right)-1\right) *$ Light $\left._{t}\right) * 100 /$ Total Light $\left.t\right)$
} 
that Mozambique's GDP in 2015 (14.8 billion USD) would have been $15 \%$ - $25 \%$ lower. ${ }^{30}$ An alternative way is looking at growth impacts; as the landmine clearance process lasted 23 years, these tabulations suggest an impact of landmine clearance of around $0.7-1.0$ percentage points per year.

\subsection{Coordination and Prioritization}

We now ask how the market access would have changed if demining operators had followed a coordinated strategy (under perhaps the United Nations or the National Government) that would prioritize clearance of localities along the transportation network, as clearing this type of contamination seems to have had larger local benefits (Table 5) and strong externalities (Table 7).

Using the spatial general equilibrium model of intra-country (across-locality) trade and the econometric estimates, we simulate an alternative demining process that follows naturally from a simple reading of Mozambique's history and its economic geography. The counterfactual works as follows: In the first period $(1992-1999)$ demining operators prioritize clearance along the three development (trade) corridors, where primary roads and railroads connect Maputo, Beira and Nampula to the interior. In the second period $(2000-2007)$, landmine clearance continues across the three development corridors and then targets the main highway (N1) connecting the South to the Central coastal areas and the North. In the third period $(2008-2015)$ clearance focuses on localities where there is still contamination of paved, unpaved roads and trails (with this order). To be consistent with the observed number of localities cleared each period, we match the number of simulated localities to the cleared ones (e.g., the simulation clears 39 localities in the first-phase, the exact number of cleared localities in reality).

Table 10 reports the average change of the actual and the simulated market access in the end of each of the three phases of demining (1999, 2007, and 2015). The table gives changes in market access fixing luminosity and infrastructure to the 1992 levels so as to isolate the impact of landmines clearance. In the end of each period, we compare the difference between the change in the actual market access and its simulated counterpart.

Panel $A$ focuses on the entire clearance period (1992-2015). Naturally, actual changes in market access are identical to the simulated changes, as by 2015 all contaminated localities (in total 855) are cleared both in reality and in our simulation. The mean (median) increase in market access is 1.21 (0.83).

Panel $B$ looks at the $1992-1999$ period. During the first phase of demining only 39 localities were fully cleared. The average increase in log market access is thus small, 0.11. The increase in market access under the counterfactual demining process is moderately higher, 0.13 , as we impose that the same small number of localities are cleared.

\footnotetext{
${ }^{30}$ Unfortunately information on the financial cost of landmine clearance going back to 1992 is incomplete and available only from secondary sources. However, it seems that on average 10-15 million USD dollars were spent just for clearance and technical surveys, resulting into a total cost of around $350-500$ million USD (in 2017 dollar terms).
} 


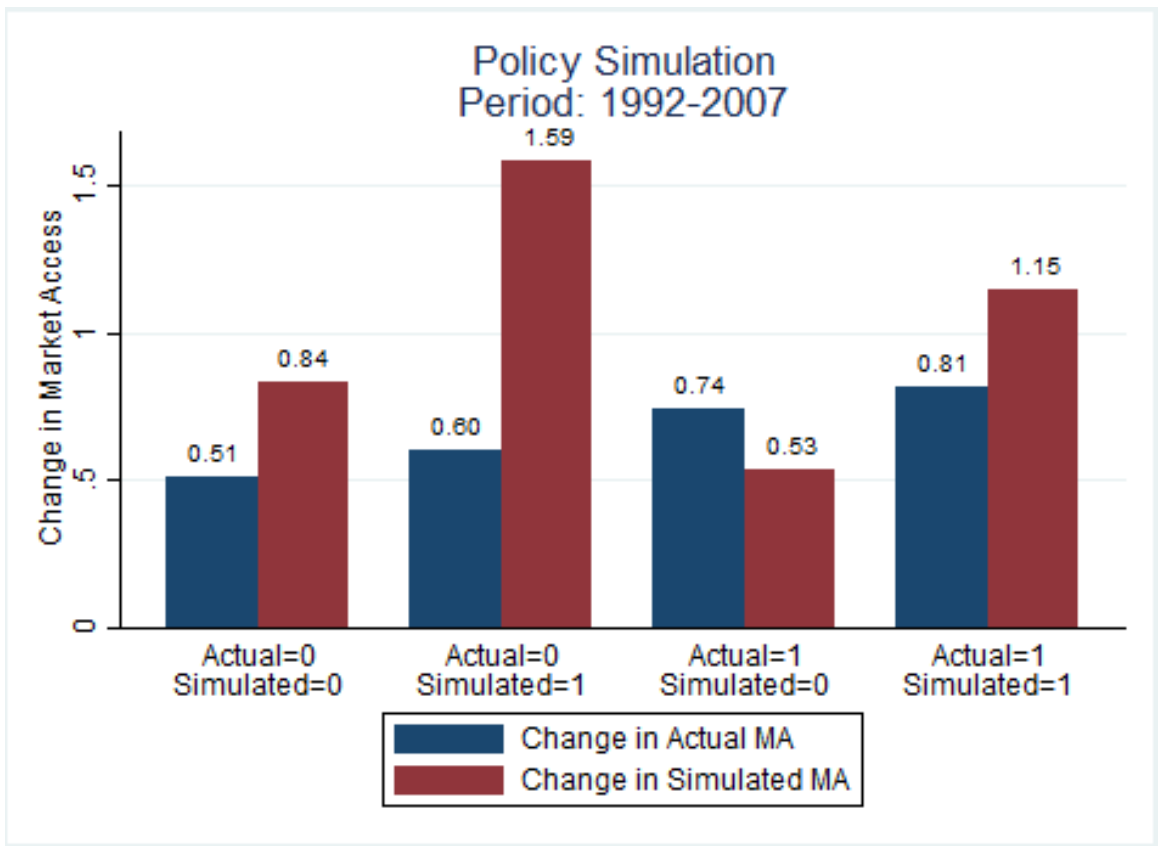

Figure 9: Policy Simulation Period 2

Panel $C$ looks at 1992-2007 period; 442 localities were fully cleared. This resulted into an average (median) increase in log market access of 0.63 (0.31). However, had the country pursued a coordinated approach targeting the central nodes of its pre-war transportation network, the increase in market access would have been substantially higher. The mean increase in log market access of the simple counterfactual is $0.99,50 \%$ higher than the realized one. The median increase of log market access in the counterfactual is $0.56,80 \%$ higher than the actual one.

Figure 9 provides a more-in-depth illustration of the costs of the absence of centralization and prioritization, while at the same time illustrates the sizable spillovers of landmine clearance. The figure plots the average of the realized and the counterfactual change in log "market access" for 4 groups of localities in 2007, the end of the second phase of demining when only half of contaminated localities were cleared. $(i)$ Localities that were cleared both in reality and in our counterfactual (156 observations). These are localities close to the three development corridors and along the main SouthCentre highway. (ii) Localities that were actually cleared by 2007, but are not prioritized by our counterfactual (286 localities). (iii) Contaminated localities that had not been cleared by 2007 (i.e., cleared during 2008 - 2015), but are cleared in our simulation (286 localities). (iv) Contaminated localities that had not cleared by 2007 and that are not prioritized in our simulation. These are, by definition, localities far from the three development "corridors" and the main highway that were cleared post-2008.

Let us start with localities that were neither cleared in reality nor in our counterfactual by 2007 . Log market access increased by 0.51 , as they gained from clearance operations in other interconnected 
areas. Had clearance targeted the central nodes of the transportation system, log market access would have increased, way more, as the average increase in counterfactual log market access is 0.84 . Median changes in $\log$ market access (not shown) are also sizable, 0.47 for the counterfactual and 0.27 for actual.

Turning now to localities that were fully cleared in reality and are also cleared in the counterfactual by 2007 , the average (median) increase in realized log market access is 0.81 (0.56). But in our counterfactual, the mean (median) increase is larger, $1.15(0.97)$, as the simulated market access gets a boost from clearance of other central nodes (localities).

The increase in actual log market access in the localities that had been treated in reality in 2007, but are not prioritized in our counterfactual is higher. The average change of realized log market access is 0.74 , while the change in the counterfactual log market access is 0.53 (medians 0.49 versus 0.25). The "mirror" image of this difference is comparing actual and counterfactual market access in localities that were not cleared in reality, but are cleared in our counterfactual. The average (median) increase of realized log market access is 0.60 (0.24). Market access increased in spite of the absence of clearance, as these localities benefited from landmine removal operations in other places. But the counterfactual increase in log market access is significantly larger, 1.59 (and the median 1.21).

While this simple counterfactual suggests sizable losses associated with the non-coordinated and with lack of prioritization process of landmine clearance, a word of caution is in order. Our counterfactual analysis does not take into account humanitarian aspects, local at-the-time information, coordination and central planning costs. Hence, this policy counterfactual is not meant to supplant existing prioritization strategies, but rather to complement them. The simulations offer an informative, hands-off approach in crafting a sound demining strategy in the presence of economic externalities, which the Mozambican case suggests that are sizable, though not much-considered by the landmine clearance community at that time.

\section{Discussion}

We conclude with a discussion of the policy implications and possible paths for future research.

\subsection{Policy}

While clearly more research is needed to understand the economic effects of landmines, our analysis from Mozambique, the only so far heavily contaminated by landmines country to be declared landmine free, carries some policy implications. First, demining operators and governments should take into account the fact that clearance boosts economic performance in relatively large towns, areas close to roads and railroads, and local trade hubs. District prioritization is a complex in reality process that factors in various considerations. The Mozambique experience suggests that the economic potential -that is high in towns and cities- should be one of them. Given 'economics' considerable research on 
the benefits of transportation infrastructure on regional trade, this finding may not be that surprising. Yet, it stands in contrast to the traditional modus operandi of demining operators that -if anythingoften prioritized remote rural areas.

Second, the stark comparison of the small-to-moderate "local" effects of demining with the large "economy-wide" estimates and the associated counterfactual policy simulations revealing large losses from the scattered and non-coordinated process that characterized Mozambique in the 1990s and early $2000 \mathrm{~s}$, stresses the importance of coordination and central planning. This has immediate implications for the design of mine action programmes in Cambodia, Afghanistan, Colombia, and other heavilymined countries, where the international community is currently working on.

Third, our findings offer some backing to the efforts of the international community to persuade governments to expand the International Mine Ban Treaty on Anti-Personnel landmines of 1999 to also cover anti-tank (anti-vehicle) landmines. By debilitating the transportation network, anti-tank landmines hinder economic recovery, as development is fueled by the flow of goods, people, and ideas.

\subsection{Future Work}

Landmines affect the lives of millions around the world. Cheap to obtain and easy to manufacture, their appeal to warring parties, militias, and rebels is likely to persist. This paper is a first step towards a better understanding of landmines' legacy shedding light on the consequences of demining on local and aggregate economic activity in Mozambique. Clearly, we need more research to assess the mechanisms at work. Using individual-level data it will be illuminating to examine how the clearance of landmines and of other improvised explosive devices shapes poverty, land use, agricultural productivity, health, as well as educational outcomes. Moreover, anecdotes from the contaminated communities suggest that landmines entail sizable environmental costs, hence, future work could assess their role on livestock, wildlife, and conservation.

Landmine contamination is one of the many deleterious facets of civil warfare; not limited to child soldiering, refugee flows, forced labor, extortion, violence against women and children, and mutilations. Future research should dig deeper into these aspects, understand their heritage and spatial interdependencies, and explore how they interact with each other both in the context of conflict as well in the context of post-conflict recovery. 


\section{References}

Alder, S. (2017): "Chinese roads in India: The effect of transport infrastructure on economic development," Work. Pap., Univ. North Carolina, Chapel Hill.

Arcand, J.-L., A.-S. Rodella-Boitreaud, and M. Rieger (2014): "The impact of land mines on child health: evidence from Angola," Economic Development and Cultural Change, 63(2), 249-279.

Arkolakis, C., A. Costinot, and A. Rodríguez-Clare (2012): "New trade models, same old gains?," The American Economic Review, 102(1), 94-130.

Bates, R. H. (2007): "Political conflict and state failure," The Political Economy of Economic Growth in Africa, 1960-2000.

Blattman, C., and E. Miguel (2010): "Civil war," Journal of Economic literature, 48(1), 3-57.

Cameron, M., J. Gibson, K. Helmers, S. Lim, J. Tressler, and K. Vaddanak (2010): "The value of statistical life and cost-benefit evaluations of landmine clearance in Cambodia," Environment and Development Economics, 15(4), 395-416.

Collier, P., and J. W. Gunning (1999): "Explaining African economic performance," Journal of economic literature, 37(1), 64-111.

Collier, P., And A. Hoeffler (2007): "Civil War," Handbook of defense economics, 2, 711-739.

Collier, P., and N. Sambanis (2005): "Understanding Civil War,(2 vols.)," Washington: The World Bank.

Costinot, A., and A. Rodriguez-Clare (2014): "Trade theory with numbers," Gopinath, G., Helpman, E. and K. Rogoff.(eds.) Handbook of International Economics, 4.

Davis, D. R., And D. E. Weinstein (2002): "Bones, bombs, and break points: the geography of economic activity," The American Economic Review, 92(5), 1269-1289.

Dell, M. (2015): "Trafficking networks and the Mexican drug war," The American Economic Review, 105(6), 1738-1779.

Dell, M., And P. Querubin (2017): "Nation building through foreign intervention: Evidence from discontinuities in military strategies," The Quarterly Journal of Economics, 1, 64.

Domingues, P., Et Al. (2011): "A Database on the Mozambican Civil War," Peace Economics, Peace Science and Public Policy, 17(1), 5.

Donaldson, D. (2015): “The gains from market integration," economics, 7(1), 619-647. 
(2018): "Railroads of the Raj: Estimating the impact of transportation infrastructure," American Economic Review, 108(4-5), 899-934.

Donaldson, D., And R. Hornbeck (2016): "Railroads and American economic growth: A market access approach," The Quarterly Journal of Economics, 131(2), 799-858.

Duflo, E., And A. BAnerJee (2011): Poor economics: a radical rethinking of the way to fight global poverty.

Easterly, W. (2009): "Can the west save Africa?," Journal of economic literature, 47(2), 373-447.

Easterly, W., And T. Pfutze (2008): "Where does the money go? Best and worst practices in foreign aid," Journal of Economic Perspectives, 22(2), 29-52.

EAton, J., And S. Kortum (2002): "Technology, geography, and trade," Econometrica, 70(5), 1741-1779.

Elliot, G., And G. Harris (2001): "A cost-benefit analysis of landmine clearance in Mozambique," Development Southern Africa, 18(5), 625-633.

Fogel, R. W. (1964): "Railroads and American Economic Growth," .

Geneva International Center for Humanitarian Demining (2005): "A Review of Ten Years Assistance to the Mine Action Programmes Mozambique," Discussion paper.

Government of Mozambique (2008): "Request for n Extension of the Deadline for Completing the Destruction of Anti-Personnel Mines in Mined Areas," Discussion paper.

Halo Trust (1994): “The Halo Trust / UNOHAC Mines Survey of Mozambique," .

(2007): "Baseline Assessment Of Minefields in South \& Central Mozambique," .

(2007a): "The Mine Impact Free Survey of Northern Mozambique Final Report, October 20042007," Discussion paper.

Harari, M., and E. La Ferrara (2018): "Conflict, climate and cells: A disaggregated analysis," Review of Economics and Statistics.

Henderson, J. V., A. Storeygard, and D. N. Weil (2012): "Measuring economic growth from outer space," The American Economic Review, 102(2), 994-1028.

Human Rights Watch (1997): "Still Killing. Landmine in Southern Africa," Discussion paper.

ICRC (2002): "Anti-vehicle mines: effects on humanitarian assistance and civilian populations," Discussion paper, International Committee of the Red Cross.

IGC (2018): "Escaping the fragility trap," Discussion paper, International Growth Center. 
Jedwab, R., And A. Storeygard (2018): "The Heterogeneous Effects of Transportation Investments: Evidence from sub-Saharan Africa 1960-2010," Discussion paper.

Keeley, R. (2006): The Economics of Landmine Clearance. dissertation.de.

LandmineMonitor (2015): "Landmine Monitor 2015," Discussion paper, International Campaign to Ban Landmines (ICBL) and the Cluster Munition Coalition (CMC).

(2016): "Landmine Monitor 2016," Discussion paper, International Campaign to Ban Landmines (ICBL) and the Cluster Munition Coalition (CMC).

(2017): "Landmine Monitor 2017," Discussion paper, International Campaign to Ban Landmines (ICBL) and the Cluster Munition Coalition (CMC).

LI, X., D. LI, H. Xu, ANd C. Wu (2017): "Intercalibration between DMSP/OLS and VIIRS night-time light images to evaluate city light dynamics of Syrias major human settlement during Syrian Civil War," International Journal of Remote Sensing, 38(21), 5934-5951.

Lin, E. (2016): "How War Changes Land: The long-term economic impact of US bombing in Cambodia,"

Merrouche, O. (2008): "Landmines and poverty: IV evidence from Mozambique," Peace Economics, Peace Science and Public Policy, 14(1).

Michalopoulos, S., and E. Papaioannou (2016a): "Historical Legacies and African Development," .

Michalopoulos, S., and E. Papaionnnou (2016b): "The long-run effects of the scramble for Africa," The American Economic Review, 106(7), 1802-1848.

_ (Forthcoming): "Spatial Patterns of Development: A Meso Approach," Annual Review of Economics.

Miguel, E., And G. Roland (2011): "The long-run impact of bombing Vietnam," Journal of development Economics, 96(1), 1-15.

PÉrez-Cervantes, F. (2014): "Railroads and economic growth: A trade policy approach," Discussion paper, Working Papers, Banco de México.

Robinson, D. A. (2006): Curse on the land: a history of the Mozambican civil war. University of Western Australia Crawley.

SACHS, J. (2005): The end of poverty: How we can make it happen in our lifetime. Penguin UK.

Sundberg, R., and E. Melander (2013): "Introducing the UCDP georeferenced event dataset," Journal of Peace Research, 50(4), 523-532. 
Tables 


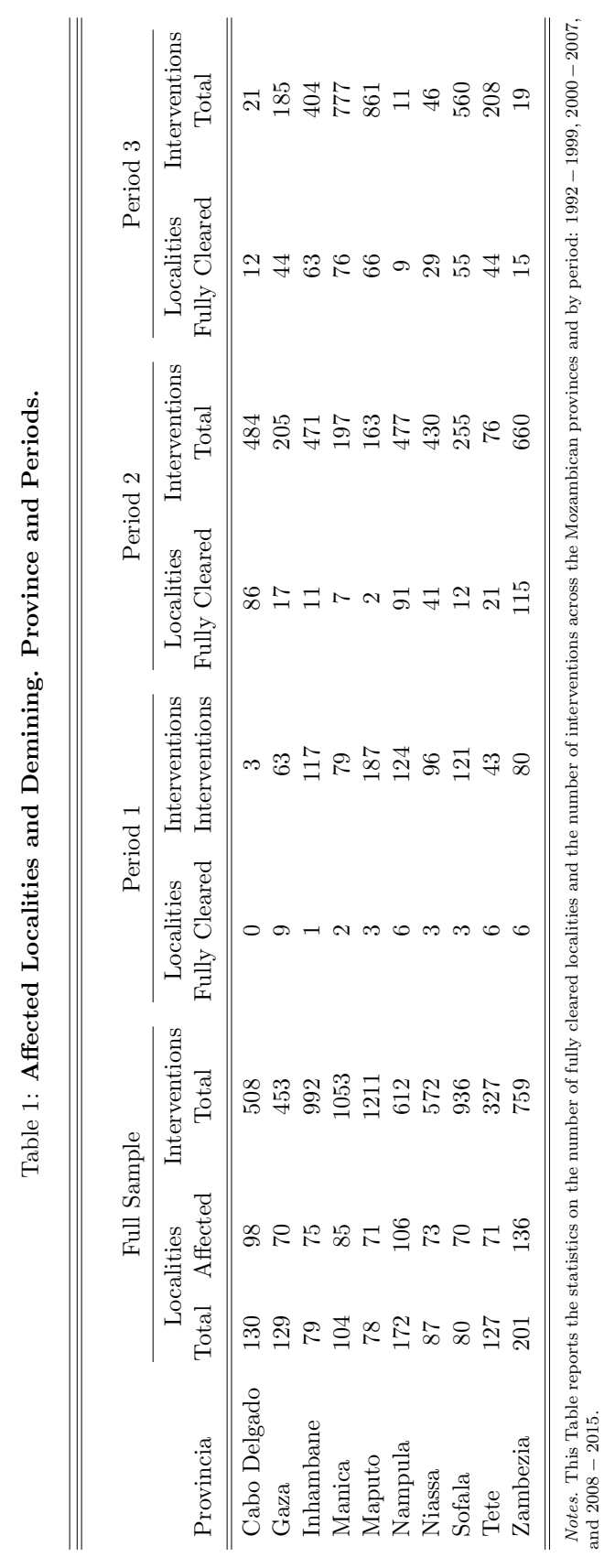


Table 2: Descriptive Statistics

\begin{tabular}{|c|c|c|c|c|c|c|}
\hline & \multicolumn{6}{|c|}{ Full Sample } \\
\hline & Observations & Mean & Standard Deviation & Median & Min & $\operatorname{Max}$ \\
\hline Share of Contaminated & & & & & & \\
\hline localities in 1992 & 1187 & 0.720 & 0.449 & 1 & 0 & 1 \\
\hline Number of Threats in 1992 & 1187 & 6.253 & 14.164 & 2 & 0 & 238 \\
\hline Lit 1992 & 1187 & 0.098 & 0.297 & 0 & 0 & 1 \\
\hline Lit 1999 & 1187 & 0.177 & 0.382 & 0 & 0 & 1 \\
\hline Lit 2007 & 1187 & 0.227 & 0.419 & 0 & 0 & 1 \\
\hline Lit 2015 & 1187 & 0.422 & 0.494 & 0 & 0 & 1 \\
\hline Log Luminosity 1992 & 1187 & -10.579 & 2.924 & -11.5 & -11.5 & 2.51 \\
\hline Log Luminosity 1999 & 1187 & -9.858 & 3.736 & -11.5 & -11.5 & 2.83 \\
\hline Log Luminosity 2007 & 1187 & -9.344 & 4.197 & -11.5 & -11.5 & 3.11 \\
\hline Log Luminosity 2015 & 1187 & -7.633 & 4.800 & -11.5 & -11.5 & 3.15 \\
\hline Paved Road 1973 (dummy) & 1187 & 0.171 & 0.377 & 0 & 0 & 1 \\
\hline Unpaved Road 1973 (dummy) & 1187 & 0.021 & 0.144 & 0 & 0 & 1 \\
\hline Trail 1973 (dummy) & 1187 & 0.660 & 0.474 & 1 & 0 & 1 \\
\hline Railway 1992 (dummy) & 1187 & 0.130 & 0.336 & 0 & 0 & 1 \\
\hline Navigable River (dummy) & 1187 & 0.228 & 0.420 & 0 & 0 & 1 \\
\hline Cantinas (dummy) & 1187 & 0.584 & 0.493 & 1 & 0 & 1 \\
\hline Civil War (dummy) & 1187 & 0.158 & 0.365 & 0 & 0 & 1 \\
\hline Log MA Light 1992 & 1187 & -15.767 & 3.127 & -16.4 & -22.3 & -5.54 \\
\hline Log MA Light 1999 & 1187 & -14.104 & 3.274 & -14.6 & -20.9 & -4.49 \\
\hline Log MA Light 2007 & 1187 & -12.809 & 3.190 & -13.2 & -20.9 & -1.75 \\
\hline Log MA Light 2015 & 1187 & -10.214 & 2.409 & -10.5 & -16 & -.765 \\
\hline
\end{tabular}

Notes: This table reports the summary statistics of the main variables at the locality level. 
Table 3: Land Mine Removal and Local Development.

\begin{tabular}{|c|c|c|c|c|c|c|c|c|}
\hline & \multicolumn{2}{|c|}{ Log Luminosity } & \multicolumn{2}{|c|}{ Lit } & \multicolumn{2}{|c|}{ Log Luminosity } & \multicolumn{2}{|c|}{ Lit } \\
\hline & $(1)$ & $(2)$ & $(3)$ & $(4)$ & $(5)$ & $(6)$ & $(7)$ & $(8)$ \\
\hline Cleared Threats & $\begin{array}{c}0.329 * * * \\
(0.073) \\
{[0.071]}\end{array}$ & & $\begin{array}{c}0.037^{* * *} * \\
(0.007) \\
{[0.080]}\end{array}$ & & $\begin{array}{c}0.469^{* * *} \\
(0.098) \\
{[0.107]}\end{array}$ & & $\begin{array}{c}0.058^{* * *} \\
(0.011) \\
{[0.129]}\end{array}$ & \\
\hline Cleared (dummy) & & $\begin{array}{c}0.373^{* * *} \\
(0.109) \\
{[0.037]}\end{array}$ & & $\begin{array}{c}0.038^{* * *} \\
(0.011) \\
{[0.038]}\end{array}$ & & $\begin{array}{c}0.755^{* * *} \\
(0.182) \\
{[0.082]}\end{array}$ & & $\begin{array}{c}0.083^{* * *} \\
(0.020) \\
{[0.088]}\end{array}$ \\
\hline Number of Localities & 1,187 & 1,187 & 1,187 & 1,187 & 1,187 & 1,187 & 1,187 & 1,187 \\
\hline Observations & 27,301 & 27,301 & 27,301 & 27,301 & 4,748 & 4,748 & 4,748 & 4,748 \\
\hline
\end{tabular}

Notes: This table reports panel fixed effects OLS estimates associating luminosity with landmine clearance. The dependent variable in columns (1)-(2) and (5)-(6) is the log of luminosity plus the half of the minimum positive value of luminosity. The dependent variable in columns (3)-(4) and (7)-(8) is an indicator that takes the value of one if the locality appears to be lit. Columns (1)-(4) report yearly specifications (1992-2015). Columns (5)-(8) focus on 4 specific years that correspond to the three main phases of landmine clearance, namely 1992, 1999, 2007 and 2015 . Cleared Threats is the logarithm of one plus the number of accumulated cleared confirmed hazardous areas (CHA) in the locality in a given year. Cleared is year an indicator variable the takes the value of 0 while the locality is contaminated and becomes 1 the (and for all subsequent years) that the locality is landmine free; the indicator equals zero for all localities that were not contaminated. All specifications include locality-specific constants and province-year specific fixed effects (constants not reported). Standard errors in parentheses are clustered at the district (admin 2) level and standardized beta coefficients [in brackets]. $* * *, * *$, and $*$ indicate statistical significance at the $1 \%, 5 \%$ and $10 \%$ level, respectively. 
Table 4: Long-Run Differences, 2015-1992

\begin{tabular}{|c|c|c|c|c|c|c|c|c|}
\hline & \multicolumn{4}{|c|}{ Log Luminosity } & \multicolumn{4}{|c|}{ Lit } \\
\hline & $(1)$ & $(2)$ & $(3)$ & $(4)$ & $(5)$ & (6) & (7) & (8) \\
\hline$\Delta$ Cleared Threats & $\begin{array}{c}0.787^{* * *} \\
(0.165) \\
{[0.189]}\end{array}$ & & $\begin{array}{c}0.753^{* * *} \\
(0.127) \\
{[0.181]}\end{array}$ & & $\begin{array}{c}0.102^{* * *} \\
(0.018) \\
{[0.223]}\end{array}$ & & $\begin{array}{c}0.094^{* * *} \\
(0.014) \\
{[0.205]}\end{array}$ & \\
\hline Cleared (dummy) & & $\begin{array}{c}0.968^{* * *} \\
(0.328) \\
{[0.093]}\end{array}$ & & $\begin{array}{c}0.777^{* * *} \\
(0.281) \\
{[0.075]}\end{array}$ & & $\begin{array}{c}0.123^{* * *} \\
(0.035) \\
{[0.107]}\end{array}$ & & $\begin{array}{c}0.089^{* * *} \\
(0.030) \\
{[0.078]}\end{array}$ \\
\hline Paved Road 1973 (dummy) & & & $\begin{array}{c}2.977^{* * *} \\
(0.342) \\
{[0.249]}\end{array}$ & $\begin{array}{c}3.165^{* * *} \\
(0.347) \\
{[0.265]}\end{array}$ & & & $\begin{array}{c}0.284^{* * *} \\
(0.038) \\
{[0.216]}\end{array}$ & $\begin{array}{c}0.308^{* * *} \\
(0.039) \\
{[0.234]}\end{array}$ \\
\hline Unpaved Road 1973 (dummy) & & & $\begin{array}{c}0.973 \\
(0.793) \\
{[0.030]}\end{array}$ & $\begin{array}{c}1.173 \\
(0.840) \\
{[0.037]}\end{array}$ & & & $\begin{array}{l}0.166^{*} \\
(0.084) \\
{[0.047]}\end{array}$ & $\begin{array}{c}0.192^{* *} \\
(0.090) \\
{[0.055]}\end{array}$ \\
\hline Trail 1973 (dummy) & & & $\begin{array}{c}1.001 * * * \\
(0.242) \\
{[0.102]}\end{array}$ & $\begin{array}{c}1.110^{* * *} \\
(0.240) \\
{[0.113]}\end{array}$ & & & $\begin{array}{c}0.101^{* * *} \\
(0.029) \\
{[0.093]}\end{array}$ & $\begin{array}{c}0.115^{* * *} \\
(0.029) \\
{[0.107]}\end{array}$ \\
\hline Railway 1973 (dummy) & & & $\begin{array}{c}0.856^{* *} \\
(0.405) \\
{[0.063]}\end{array}$ & $\begin{array}{c}0.931^{* *} \\
(0.389) \\
{[0.068]}\end{array}$ & & & $\begin{array}{c}0.034 \\
(0.045) \\
{[0.023]}\end{array}$ & $\begin{array}{c}0.045 \\
(0.042) \\
{[0.030]}\end{array}$ \\
\hline Navigable River (dummy) & & & $\begin{array}{c}0.564 \\
(0.343) \\
{[0.051]}\end{array}$ & $\begin{array}{c}0.583^{*} \\
(0.340) \\
{[0.053]}\end{array}$ & & & $\begin{array}{c}0.056 \\
(0.037) \\
{[0.046]}\end{array}$ & $\begin{array}{c}0.058 \\
(0.037) \\
{[0.048]}\end{array}$ \\
\hline Civil War (dummy) & & & $\begin{array}{c}1.764^{* * *} \\
(0.351) \\
{[0.142]}\end{array}$ & $\begin{array}{c}2.047^{* * *} \\
(0.365) \\
{[0.165]}\end{array}$ & & & $\begin{array}{c}0.129 * * * \\
(0.040) \\
{[0.094]}\end{array}$ & $\begin{array}{c}0.165^{* * *} \\
(0.042) \\
{[0.121]}\end{array}$ \\
\hline Cantinas (dummy) & & & $\begin{array}{c}0.707^{* *} \\
(0.272) \\
{[0.075]}\end{array}$ & $\begin{array}{c}0.695^{* *} \\
(0.279) \\
{[0.074]}\end{array}$ & & & $\begin{array}{l}0.058^{*} \\
(0.031) \\
{[0.055]}\end{array}$ & $\begin{array}{l}0.057^{*} \\
(0.032) \\
{[0.054]}\end{array}$ \\
\hline Log - Population Density 1980 & & & $\begin{array}{c}0.505^{* * *} \\
(0.126) \\
{[0.168]}\end{array}$ & $\begin{array}{c}0.596^{* * *} \\
(0.127) \\
0.198]\end{array}$ & & & $\begin{array}{c}0.050 * * * \\
(0.015) \\
{[0.151]}\end{array}$ & $\begin{array}{c}0.062^{* * *} \\
(0.015) \\
0.186]\end{array}$ \\
\hline Log - Luminosity & & & $\begin{array}{c}-0.761 * * * \\
(0.038) \\
{[-0.495]}\end{array}$ & $\begin{array}{c}-0.776^{* * *} \\
(0.039) \\
{[-0.505]}\end{array}$ & & & & \\
\hline Lit (dummy) & & & & & & & $\begin{array}{c}-0.833^{* * *} \\
(0.042) \\
{[-0.500]}\end{array}$ & $\begin{array}{c}-0.850^{* * *} \\
(0.044) \\
{[-0.510]}\end{array}$ \\
\hline Log - Land & & & $\begin{array}{c}-1.169^{* * *} \\
(0.153) \\
{[-0.290]}\end{array}$ & $\begin{array}{c}-0.937 \text { *** } \\
(0.156) \\
{[-0.232]}\end{array}$ & & & $\begin{array}{c}-0.074^{* * *} \\
(0.017) \\
{[-0.166]}\end{array}$ & $\begin{array}{c}-0.043^{* *} \\
(0.018) \\
{[-0.098]}\end{array}$ \\
\hline Locality FE & Yes & Yes & Yes & Yes & Yes & Yes & Yes & Yes \\
\hline Province FE & Yes & Yes & Yes & Yes & Yes & Yes & Yes & Yes \\
\hline R-squared & .0686 & .047 & .433 & .416 & .0704 & .0397 & .352 & .329 \\
\hline Observations & 1,077 & 1,077 & 1,077 & 1,077 & 1,077 & 1,077 & 1,077 & 1,077 \\
\hline
\end{tabular}

Notes: This table reports long-run difference OLS specification estimates associating changes in luminosity (over the period 20151992) to demining activities. The dependent variable in columns (1)-(4) is the change in the log luminosity plus the half of the minimum positive value of luminosity. The dependent variable is columns (5)-(8) is the change in the lit indicator. Columns (1)-(2) and (5)-(6) report unconditional specification estimates. Columns (3)-(4) and (7)-(8) include a rich set of control variables, namely: indicator variables that take the value of one when a locality is endowed with features of the 1973 transportation network (paved road, unpaved road, trails, and railway); indicator variables for a navigable river, colonial commercial towns (Cantinas), and for localities affected by major civil war incidents. The set of control variables also include log 1980 population density, log luminosity in 1992, and log land area. All specifications include province fixed effects (constants not reported). Standard errors in parentheses are clustered at the district (admin 2) level and standardized beta coefficients [in brackets]. ${ }^{* * *},{ }^{* *}$, and $*$ indicate statistical significance at the $1 \%, 5 \%$ and $10 \%$ level, respectively. 
Table 5: Heterogeneity. GIS-based Categories.

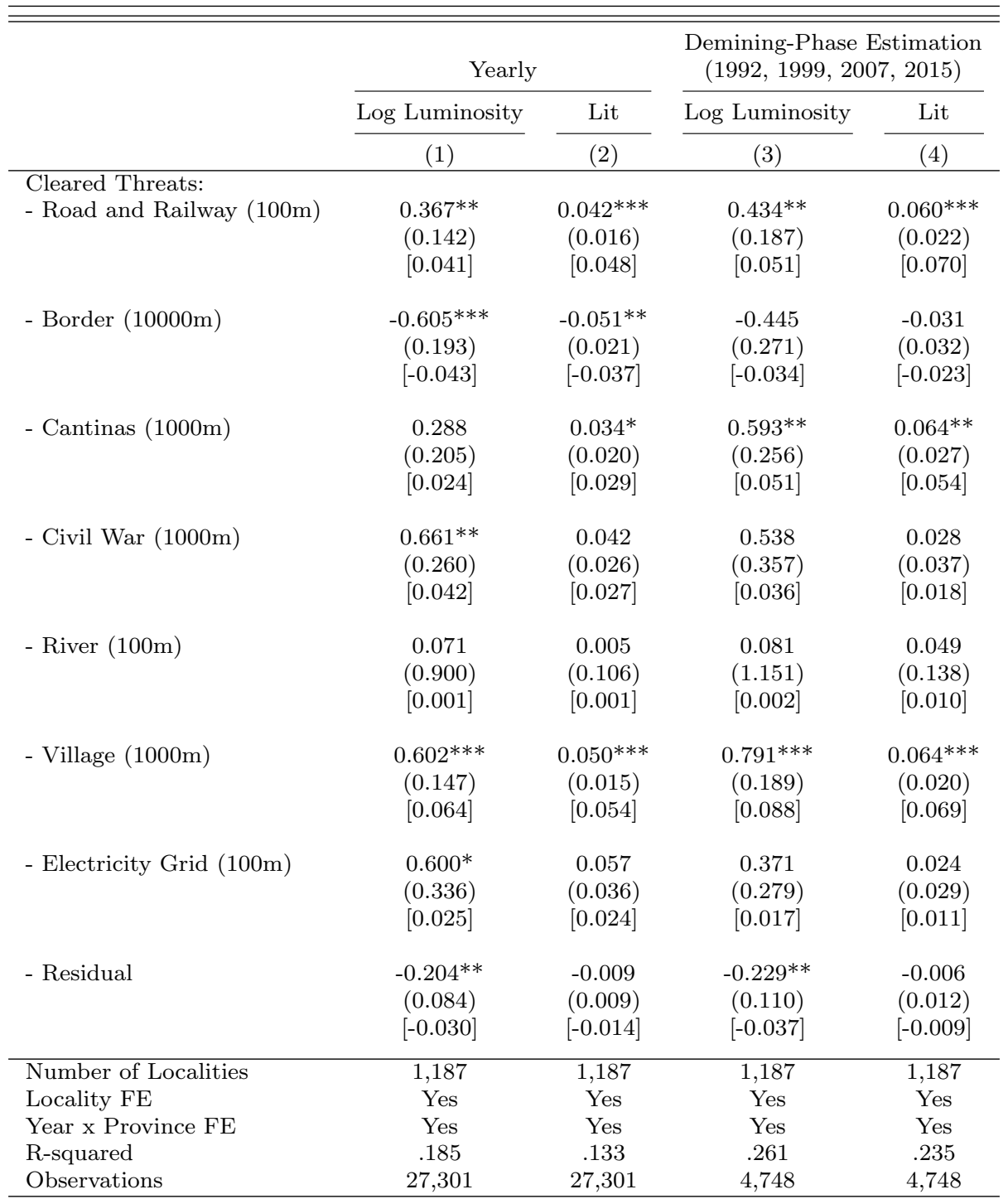

Notes. This table reports panel fixed effects OLS estimates exploring whether the association between demining activities and local development varies by the type of CHA categories cleared. The dependent variable in columns (1)-(2) is the log of luminosity plus the half of the minimum positive value of luminosity. The dependent variable is columns (3)-(4) is an indicator that takes the value of one if the locality is lit. Columns (1)-(2) report yearly specification estimates (1992-2015). Columns (3)-(4) ) focus at 4 specific years that correspond to the three main phases of landmine clearance, namely 1992, 1999, 2007 and 2015. We split our variable of interest the Number of Accumulated Cleared Threats into seven non-mutually exclusive categories, according to some GIS-based distance thresholds. We classify the different categories as follows: i) Roads and Railways if a threats centroid is within 100 meters from a road or a railway; ii) Border if a threats centroid is less than 10,000 meters from the country border; iii) Cantinas if a threats centroid is less than 1,000 meters from a village with a colonial commercial hub; iv) Civil War if a threats centroid is in a buffer of 1,000 meters from an event of the Civil War; v) River if a threats centroid is less than 100 meters distant from a river or lake; vi) Village if a threats centroid is within 1,000 meters from a village; and Electricity Grid if a threats centroid is in a buffer of 100 meters from the electric grid or pylon. The Residual category includes all the remaining threats. All specifications include locality-specific constants and province-year specific fixed effects (constants not reported). Standard errors in parentheses are clustered at the district (admin 2) level and standardized beta coefficients [in brackets]. ***,**, and * indicate statistical significance at the $1 \%, 5 \%$ and $10 \%$ level, respectively. 


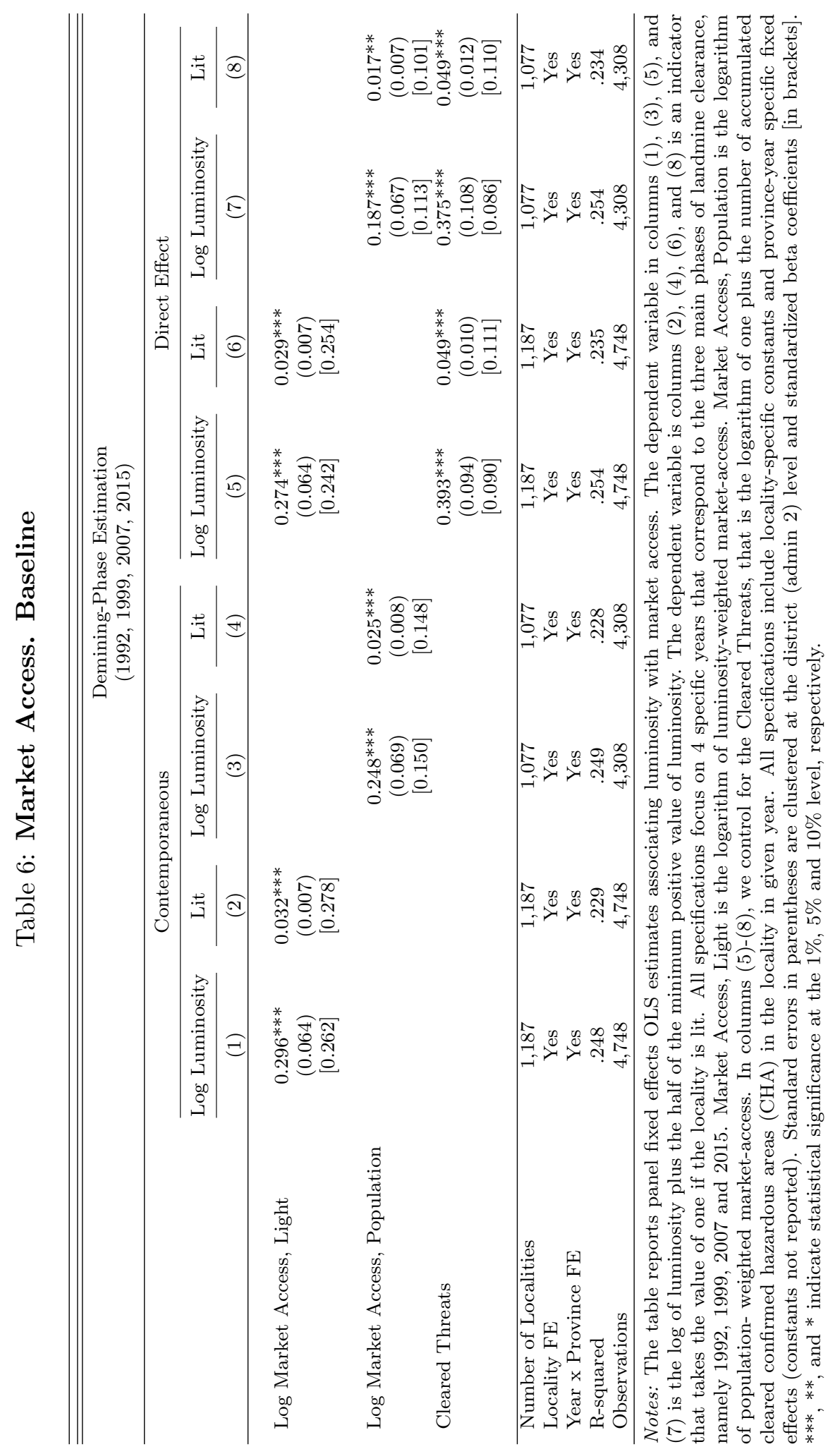


Table 7: Market Access in Non-Affected

\begin{tabular}{|c|c|c|c|c|}
\hline & \multicolumn{4}{|c|}{$\begin{array}{l}\text { Demining-Phase Estimation } \\
(1992,1999,2007,2015)\end{array}$} \\
\hline & \multicolumn{4}{|c|}{ Contemporaneous } \\
\hline & \multicolumn{2}{|c|}{ Log Luminosity } & \multicolumn{2}{|c|}{ Lit } \\
\hline & $(1)$ & $(2)$ & $(3)$ & $(4)$ \\
\hline Log Market Access, Light & $\begin{array}{c}0.270^{* * *} \\
(0.099) \\
{[0.279]}\end{array}$ & $\begin{array}{c}0.032^{* * *} \\
(0.011) \\
{[0.318]}\end{array}$ & & \\
\hline Log Market Access, Population & & & $\begin{array}{c}0.297^{* *} \\
(0.135) \\
{[0.208]}\end{array}$ & $\begin{array}{c}0.033^{* *} \\
(0.015) \\
{[0.223]}\end{array}$ \\
\hline Number of Localities & 332 & 332 & 291 & 291 \\
\hline Locality FE & Yes & Yes & Yes & Yes \\
\hline Year x Province FE & Yes & Yes & Yes & Yes \\
\hline R-squared & .189 & .167 & .205 & .173 \\
\hline Observations & 1,328 & 1,328 & 1,164 & 1,164 \\
\hline
\end{tabular}

Notes: The table reports panel fixed effects OLS estimates associating luminosity with market access, focusing on the localities that were never contaminated by landmines. The dependent variable in columns (1)-(2) is the log of luminosity plus the half of the minimum positive value of luminosity. The dependent variable is columns (3)-(4) is an indicator that takes the value of one if the locality is lit. All specifications focus on 4 specific years that correspond to the three main phases of landmine clearance, namely 1992, 1999, 2007 and 2015. Market Access, Light is the logarithm of luminosity- weighted market-access. Market Access, Population is the logarithm of populationweighted market-access. All specifications include locality-specific constants and province-year specific fixed effects (constants not reported). Standard errors in parentheses are clustered at the district (admin 2) level and standardized beta coefficients [in brackets]. ***,**, and * indicate statistical significance at the $1 \%, 5 \%$ and $10 \%$ level, respectively. 


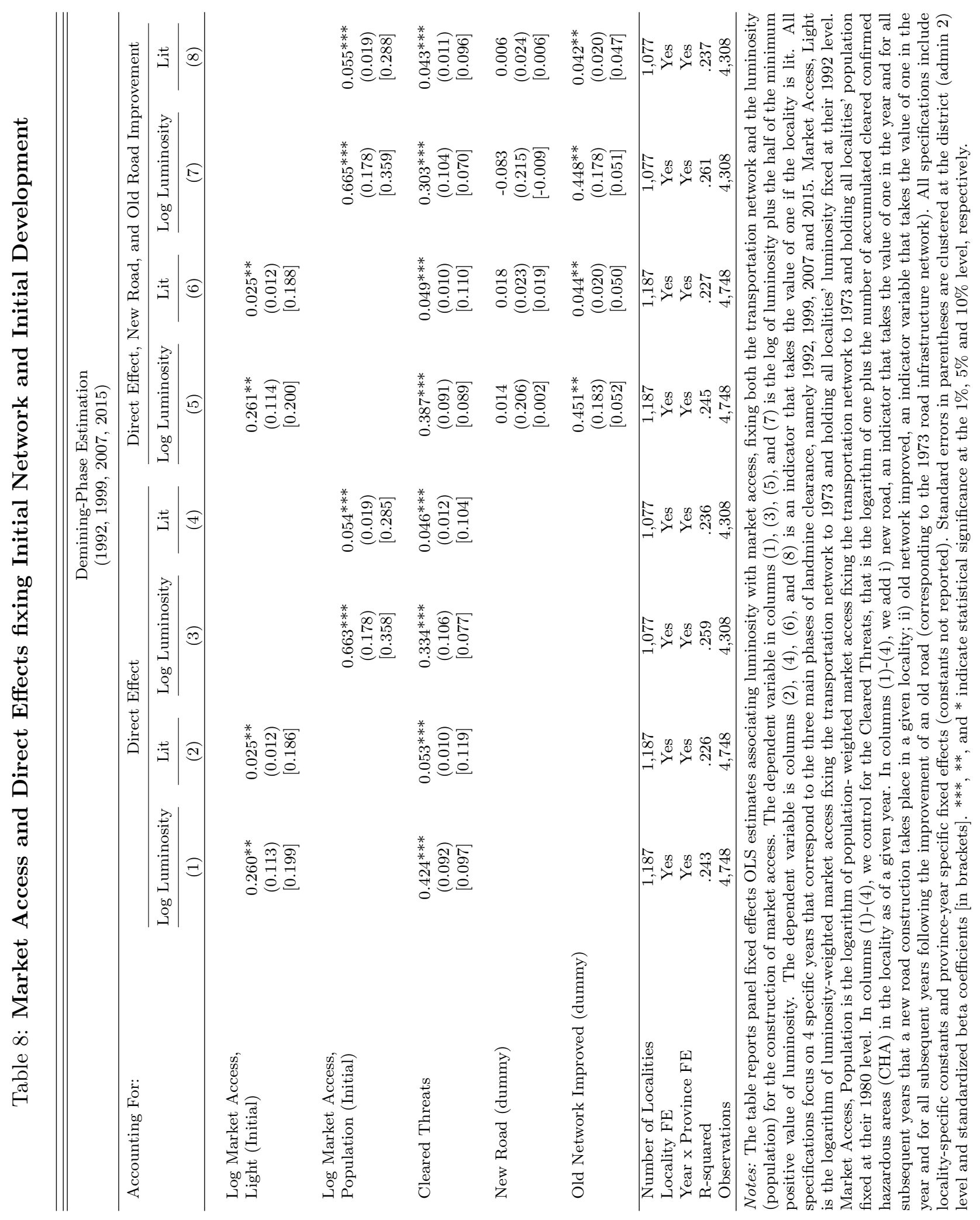


Table 9: Counterfactuals I. No Land Mine Clearance

\begin{tabular}{|c|c|c|}
\hline & $\begin{array}{l}\text { Percent Decline MA } \\
\text { without Demining Activities }\end{array}$ & $\begin{array}{l}\text { Percent Decline in Luminosity } \\
\text { without Demining Activities }\end{array}$ \\
\hline Market Access, Light & \multicolumn{2}{|c|}{$2007(\mathrm{obs}=1187)$} \\
\hline No demining activities & 58 & $30.2(1.7)$ \\
\hline $\begin{array}{l}\text { No demining activities \& } \\
\text { Assuming the Luminosity Distribution in } 1992\end{array}$ & 62.3 & $41.9(1.7)$ \\
\hline Market Access, Light & \multicolumn{2}{|c|}{$2015(\mathrm{obs}=1187)$} \\
\hline No demining activities & 59.4 & $58.7(2.4)$ \\
\hline $\begin{array}{l}\text { No demining activities \& } \\
\text { Assuming the Luminosity Distribution in } 1992\end{array}$ & 75.3 & $70.4(1.7)$ \\
\hline
\end{tabular}

Notes. Each row reports the counterfactual impact on luminosity of under the scenario that the problem of landmines contamination was unsolved. Panel A reports the counterfactual stopping in 2007; while Panel B give the counterfactual results for 2015. In the first row of each panel, the landmines are on the ground and the actual luminosity shares are used for computing the counterfactual. In the second row, landmines contamination is present but locality luminosity shares are fixed to their 1992 level and we redistribute the total level of luminosity in (2007) 2015 accordingly. Robust standard errors clustered by admin-2 are reported in parentheses, when available. 
Table 10: Counterfactual II. Policy Experiment Simulation

\begin{tabular}{|c|c|c|c|c|}
\hline \multirow[t]{2}{*}{ Dependent Variable } & \multicolumn{4}{|c|}{$\begin{array}{l}\Delta \text { Market Access } \\
\text { Network and Luminosity (Initial) }\end{array}$} \\
\hline & Mean & Median & Observations & $\begin{array}{c}\text { \# of Affected } \\
\text { used in Simulation }\end{array}$ \\
\hline & \multicolumn{4}{|c|}{ Period: 1992-2015 } \\
\hline $\begin{array}{l}\text { Actual (log) } \\
\text { Simulated }(\log )\end{array}$ & $\begin{array}{l}1.21 \\
1.21\end{array}$ & $\begin{array}{l}0.83 \\
0.83\end{array}$ & $\begin{array}{c}1187 \\
1187 \\
\text { Period: } 1992-1 \\
\end{array}$ & $\begin{array}{l}855 \\
855\end{array}$ \\
\hline $\begin{array}{l}\text { Actual }(\log ) \\
\text { Simulated }(\log )\end{array}$ & $\begin{array}{l}0.11 \\
0.13\end{array}$ & $\begin{array}{l}0.00 \\
0.01\end{array}$ & $\begin{array}{l}1187 \\
1187\end{array}$ & $\begin{array}{l}39 \\
39\end{array}$ \\
\hline & \multicolumn{4}{|c|}{ Period: 1992-2007 } \\
\hline $\begin{array}{l}\text { Actual }(\log ) \\
\text { Simulated }(\log )\end{array}$ & $\begin{array}{l}0.63 \\
0.99\end{array}$ & $\begin{array}{l}0.31 \\
0.56\end{array}$ & $\begin{array}{l}1187 \\
1187\end{array}$ & $\begin{array}{l}442 \\
442\end{array}$ \\
\hline
\end{tabular}

Notes. This Table reports the results of a policy experiment simulation, comparing the change of the actual Market Access with its simulated counterpart. The simulation prioritizes the demining interventions as follows: i) in the first period, demining activities take place on the three main corridors starting from Maputo, Beira, and Nacala; ii) in the second period, landmine clearance targets the N1 highway, paved roads, unpaved roads and trails; iii) in the last period, all the rest of the country is cleared. In the first two periods, we match the number of simulated cleared localities to the actual cleared ones $(39,442)$. All the Market Access measures are obtained by focusing on the predetermined components of market access i) the transportation network is fixed to the one available in 1973 and ii) the development proxies weighting the bilateral transportation costs are held fixed to their 1992 values. Actual (log) is the change in log Market Access weighted by the total luminosity in 1992 in all the destination localities. Simulated (log) is the change in log Market Access weighted by the total luminosity in 1992 obtainable under the simulated prioritization of demining efforts. 